\title{
PAREJAS DE REYES HISPANOS EN LA ANTIGÜEDAD Y LA ALTA EDAD MEDIA: CUESTIONES COMPARATIVAS, TIPOLÓGICAS Y GENÉTICAS
}

\author{
MARCO V. GARCÍA QUINTELA \\ Universidad de Santiago de Compostela
}

\begin{abstract}
Resumen
Se estudian menciones a parejas de reyes hispanos de la Segunda Guerra Púnica y se constata la existencia de otras parejas o grupos de reyes en los reinos cristianos alto medievales. Se interpretan estos datos con comparaciones que sugieren la existencia de la institución del «asociado del rey» atestiguada en otros lugares. Se discuten las posibilidades de una interpretación genética recurriendo a una herencia céltica o germánica y se propone una interpretación basada en la tipología de las situaciones atestiguadas, son reyes jefes de guerra. Ambas explicaciones no son contradictorias y en apéndice se recogen indicios de la existencia de una institución pancéltica de asociación real -que no sería exclusiva de esta cultura y que no explicaría necesariamente todos los hechos hispanos discutidos.
\end{abstract}

\section{Palabras clave}

Realeza, indoeuropeos, celtas, Hispania, protohistoria, Alta Edad Media.

\begin{abstract}
This paper studies pairs of Spanish kings during the Second Punic War, and also other pairs or groups of kings that existed in Early Medieval Spanish Christian kingdoms. Comparative data suggest the existence of the institution of the "associated king». I discuss the possibilities of a genetic explication by the Celtic or Germanic heritage, and, secondly, I propose an alternative typological explication, our kings are war leaders. Both explications are not self-contradictory, and as appendix we survey evidences of a pan Celtic institution, that of «associated king» - it was not only Celtic and it doesn't explain every Spanish fact under examination.
\end{abstract}

Key Words

Kingship, Indo-Europeans, Celts, Spain, protohistory, High Middle Age. 
Hace años, J. Caro Baroja compiló y examinó sistemáticamente los testimonios acerca de los reyes de la Hispania antigua presentes en las fuentes literarias ${ }^{1}$. De su lectura se aprecia que, si dejamos aparte el mito de Gárgoris y Habis sobre el origen de la realeza tartesia, y con ella de la civilización en general ${ }^{2}$, estos testimonios son extraordinariamente sucintos. En muchas ocasiones no tenemos más que nombres asociados a una fórmula que indica que son reyes, pero no pocas veces estos personajes se designan con el diminutivo/despectivo regulo, como si nuestra fuente dudase de la pertinencia de la palabra rex para referirse a ellos. Probablemente porque no eran, a juicio del autor o de sus informantes, lo suficientemente poderosos, ricos, notables, dignos... como para recibir el término rex en sentido pleno. En estas condiciones es casi imposible avanzar hacia una comprensión de la organización y sentido institucional de estas realezas.

En este panorama decepcionante para el análisis destacan, sin embargo, los datos relativos a Indíbil y Mandonio de los ilergetes y a Corbis y Orsua, de una mal localizada ciudad de Ibes o Ides. Sobre los primeros disponemos de testimonios dispersos en Polibio y Tito Livio, sobre los segundos Tito Livio nos ofrece una noticia pormenorizada. Pues bien, los primeros son hermanos y los segundos primos-hermanos, hijos de hermanos que reinaron en la ciudad, cuya realeza se disputan. Además, cierto que con menos detalle, tenemos otras noticias de parejas actuando como dirigentes político-militares precisándosenos una vez que se trata de hermanos, otra que de reyes. También es significativo que todas estas informaciones remiten a un horizonte espacio-temporal muy nítido: se trata situaciones de frontera en el teatro de operaciones peninsular durante la Segunda Guerra Púnica.

1 J. CARo BARoja, «La 'realeza' y los reyes en la España Antigua», en España Antigua (Conocimiento y fantasías), Madrid 1986, pp. 135-223 (= A. TOVAR y J. CARO BAROJA, Estudios sobre la España Antigua, Madrid 1971, pp. 51-159).

Estoy en deuda con J.M. Andrade Cernadas y F. Delpech por sus comentarios y sugerencias como medievalistas a una primera redacción de este trabajo, los errores que pueda haber son, en cualquier caso, exclusivamente míos.

${ }^{2}$ Estudiado exhaustivamente desde diversos puntos de vista, entre otros por el propio CARO BAROJA, op. cit., pp. 169-72 y en último lugar por F. GASCÓ, «Gárgoris y Habis: la leyenda de los orígenes de Tarteso», Revista de Estudios Andaluces 7, 1987, pp. 127-46; ID., «¿Curetes o cunetes? Justino XLIV, 4, 1», Gerión 5, 1987, pp. 183-94; F. JORDÁ CERDÁ, «Anotaciones marginales al mito de Gárgoris y Habis», Homenaje a J.M. Blázquez, vol. II, Madrid 1993, pp. 271-87; aportación parcial en M. GARCía Quintela, «La construcción del territorio entre iberos y celtíberos», Kalathos 18-19, 19992000, pp. 201-240, véase pp. 205-6 y 213.

${ }^{3}$ K. KRISTIANSEN, «Symbolic structures and social institutions. The twin rulers in bronze age Europe» en A. GUSTAFSSON \& H. KARLSSON (eds.), Glyfer och arkeologiska rum - en vänbok till Jarl Nordbladh, 1999, pp. 537-552. 
Cambiemos radicalmente de época y lugar. K. Kristiansen ${ }^{3}$ ha compilado una serie de datos que revelan, con un grado de precisión notable teniendo en cuenta el registro documental arqueológico que explota, la existencia de parejas de gobernantes en la Edad del Bronce escandinava (primera mitad del Segundo Milenio a. de C.) constatando, además, que desde los inicios de la Edad del Hierro esos indicios de existencia de gobernantes a pares desaparecen. Kristiansen explica el fenómeno como resultado de una importación de usos propios de las realezas del Egeo, minoicas y micénicas, a través de los Cárpatos, en donde este autor no encuentra nada semejante a lo que detecta en el Egeo y Escandinavia en cuanto a pares de jefes ${ }^{4}$. Kristiansen ubica su estudio en una perspectiva pertinente, dada la documentación que maneja, cuando se interroga sobre la posibilidad de dar un significado histórico o religioso a un registro documental que emerge repentinamente tras las tipologías arqueológicas tradicionales ${ }^{5}$. Sin embargo, con su documentación, difícilmente puede ir más allá de la consideración de una división de funciones, que se puede aceptar sin excesivos problemas, entre un jefe especialista en la guerra y otro especializado en temas religiosos.

Las parejas de reyes o generales de la protohistoria peninsular poco tienen que ver, aparentemente, con escandinavos o micénicos. Pero su existencia no es menos evidente, por no decir más, en la medida que no dependemos de la atractiva interpretación de un registro arqueológico y contamos con fuentes textuales. Sin embargo, la explicación difusionista sugerida por K. Kristiansen no explica los hechos hispanos, aunque esta apreciación no descalifica los datos escandinavos y su interpretación. La cuestión es otra.

Se trata de buscar la(s) explicación(es) que puede(n) dar cuenta del fenómeno de los gobernantes dobles. Conocemos la explicación difusionista adelantada por Kristiansen partiendo de la comparación de hechos análogos en dos horizontes espaciales grosso modo contemporáneos, a ella se podría añadir, en un plano por ahora meramente teórico, una explicación genética según la cual un uso atestigua-

\footnotetext{
${ }^{4}$ Ibídem, p. 548. En este contexto es pertinente evocar las parejas dioscúricas germánicas atestiguadas en otra documentación, véase J. DE VRIES, Altgermanische Religiongeschichte, Walter de Gruyter, Berlín, 1970 (reproducción de la segunda ed. de 1956), vol. II, pp. 244-5 y 250; N. WAGNER, «Dioskuren, Jungmannschaften und Doppelkönigtum», Zeitschrift für Deutsche Philologie 79/1, 1960 pp. 1-17, con numerosos elementos comparativos indoeuropeos e ID. IBID., 79/3, 1960, pp. 225-247, con revisión de las tradiciones germánicas de realezas dobles en pp. 229-34. D. J. WARD, The Divine Twins: An Indo-European Myth In Germanic Tradition, Berkeley y Los Ángeles 1968, pp. 44-9, reúne testimonios arqueológicos de culto a los gemelos divinos, bibliografía específica en las pp. 123-4; véase además en R. BOYER, Héros et Dieux du Nord. Guide Iconographique, París, 1997, pp. 40-1 y 79 , representaciones plásticas del dioscurismo germánico.

${ }^{5}$ KRISTIANSEN, art. cit., pp. 538-9.
} 
do en horizontes y épocas diversos, cuya sustancial semejanza establece la comparación, deriva necesariamente de su presencia ancestral en un tronco común cultural, mejor o peor establecido, cuyos rasgos heredados son los que llegan a nosotros bajo apariencias formales diversas.

En realidad las explicaciones difusionista y genética no son muy distintas. La una traza en el espacio lo que la otra ordena en el tiempo, y ambas tienen como común punto de partida, casi como un a priori intelectual, que es difícil pensar que un uso peculiar, institucional, tecnológico, intelectual, etc., pueda tener una matriz múltiple. Existe, sin embargo, otra forma de explicación habitual en la antropología social. Se trata de la derivada de la comparación entre tipos análogos en culturas diferentes, formas sociales como las propias de los cazadores recolectores, o de los agricultores de rozas, presentan un abanico de rasgos comparables susceptibles de entrar en una común discusión del tipo ${ }^{6}$. Lo mismo puede decirse con respecto a usos institucionales como el papel de los especialistas religiosos, los modos de uso del mito en la sociedad o, por detenernos en nuestro problema, las jefaturas 7 .

Estas formas de explicación de instituciones análogas no son excluyentes. La propuesta de K. Kristiansen puede ser la buena para los datos que maneja, aunque difícilmente dará cuenta de los hechos hispanos. Pero, como quiera que esos hechos tienen semejanzas con los escandinavos, habrá que contemplar otras explicaciones.

Partiendo de estas consideraciones en las páginas que siguen presentaré, en primer lugar, los testimonios antiguos sobre parejas de jefes en Hispania. Seguidamente intentaré establecer la existencia de un uso sucesorio en el que el papel de los hermanos del rey en funciones es significativo, jugando su papel en una forma específica de la figura del asociado real presente en numerosas sociedades.

Ahora bien, ese papel de los hermanos del rey reaparece, con variantes, en la Alta Edad Media hispana, cuando las realezas peninsulares están teñidas de forma importante por usos propios de las realezas germánicas, por lo demás ya influidas

\footnotetext{
${ }^{6}$ Sobre los modos de comparación es útil el tratamiento reciente de J. POUCET, Les Rois de Rome. Tradition et histoire, Bruselas, 2000, pp. 424-433. Y para la noción weberiana de tipo ideal en su aplicación a la historia antigua siempre cabe remitirse al magisterio de M.I. Finley. El tema es recurrente en su obra pero podemos circunscribirnos al capítulo «Max Weber y la ciudad-estado griega» recogido en M.I. Finley, Historia Antigua. Problemas metodológicos, Barcelona, 1986, pp. 133-56.

7 Puede verse, con bibliografía, J. C. WRIGHT, «From chief to king in Mycenaean society», Aegeum 11, 1995, pp. 63-80. Diferente es la perspectiva de M. DetIEnNe, Comparar lo incomparable. Alegato en favor de una ciencia histórica comparada, Barcelona, 2001, passim, centrada en un debate más epistemológico sobre las relaciones entre antropología e historia y en una explicación retroactiva de los interrogantes que estimularon la reflexión del autor en los últimos veinte años.
} 
por una cristianización multisecular. Esto nos llevará a discutir un doble juego de explicaciones.

Por una parte plantearemos una hipótesis genética de los usos detectados buscando en la familia céltica del gran grupo indoeuropeo. Pero la presencia de elementos germánicos en las fuentes medievales impide generalizar esa hipótesis. Por ello entra en juego otra hipótesis. Ésta se fundamenta en una comparación tipológica que de cuenta tanto de los hechos peninsulares de épocas diversas como de hechos tales como los recogidos por N. Wagner, D. Ward, K. Kristiansen y otros análogos que se puedan vislumbrar.

\section{PAREJAS DE REYES EN LA HISPANIA ANTIGUA}

Conocemos con cierto detalle dos parejas, la primera formada por los ilergetes Indíbil y Mandonio, la segunda por Corbis y Orsua. Pero también hubo otras parejas de gobernantes que aparecen más desdibujadas en nuestros testimonios.

\subsection{Indíbil y Mandonio de los Ilergetes}

Indíbil aparece por primera vez en los prolegómenos de la Segunda Guerra Púnica en Hispania. Polibio dice que fue hecho prisionero el 218 a. de C., y que destacaba como gran sostenedor de la causa de los cartagineses. Sobre su posición institucional indica simplemente que era «tirano de toda la zona centro de Iberia» ${ }^{8}$. Más adelante Tito Livio lo menciona, esta vez junto a Mandonio, especificando que anteriormente había sido regulo de los ilergetes y fue de nuevo derrotado por los romanos el 217 a. de C. ${ }^{9}$ En otro testimonio del año 211 a. de C. aparece dirigiendo una fuerza de 7.500 suesetanos contra Escipión ${ }^{10}$. Polibio ofrece más precisiones cuando en Cartago Nova cayó prisionero de Escipión junto con su familia. Indíbil y Mandonio eran hermanos e Indíbil aparece como «rey de los ilergetes». Consigue la amistad de Escipión con quien firma una alianza ${ }^{11}$. Pero los hermanos volvieron a enfrentarse con Roma aspirando a labrarse un reino tras la expulsión de los cartagineses de Hispania ${ }^{12}$. Siguen diversas peripecias hasta que ambos murieron ejecutados por los romanos el año 205 a. de C. ${ }^{13}$

\footnotetext{
8 Polibio III 76, 7.

${ }^{9}$ Livio XXII 21, 2-3.

${ }^{10}$ Livio XXV 34, 6-7.

11 Polibio X 18, 7-15; y X 37, 7-38, 5.

12 Livio XXVIII 24, 3-4.

13 Polibio XI 31-33; Livio XXIX 1, 19-3, 5; Apiano Ib. 38; Diodoro XXVI 22.
} 
Polibio vuelve a citar a Andobales cuando explica la forma habitual de actuar Roma resumiendo el contenido de una carta enviada por Publio y Lucio Escipión al rey Prusias I de Bitinia el año 190 a. de C. Allí los romanos dan cuenta de su política con respecto a los reyes:

«Pues ellos no solo se referían a su propia política sino a la política común de Roma, señalando que no solo se habían abstenido los romanos de privar a ningún príncipe existente de su reino, sino que incluso ellos mismos crearon nuevos reinos, y aumentaron el poder de otros príncipes, haciendo su territorio mucho más extenso que con anterioridad. En Iberia citaban los casos de Andobales y Kolichas...; de todos ellos decían [Publio y Lucio], habían hecho [los romanos] reyes auténticos y reconocidos en vez de pequeños e insignificantes dinastas» ${ }^{14}$.

Se trata, en definitiva, de una exposición sobre la institución del rey amicus de Roma, en la que según Polibio los Escipiones incluían a estos personajes, cosa que Polibio sabía dada su pertenencia al círculo de ese linaje romano ${ }^{15}$.

\subsection{Corbis y Orsua de Ibes}

Pasemos a los primos hermanos Corbis y Orsua, de la ciudad de Ibes o Ides, pues ambas versiones presentan los manuscritos de Tito Livio ${ }^{16}$. Leemos en el historiador romano la información sobre el duelo por el título de princeps que enfrentó a los primos ante Escipión. El pasaje ofrece indicios para considerar la existencia en Hispania de una institución simplemente aludida en otros de los testimonios que tratamos sin que en ellos sea posible ir más lejos. La explicación ofrecida por J. Caro Baroja según la cual se trataría de una sinarquía semejante a la espartana, con la diferencia de que en la ciudad griega los reyes pertenecían a linajes diferentes, me parece fuera de lugar ${ }^{17}$.

Los padres de los dos duelistas habían sido reyes de la ciudad. El padre de Orsua había sido el último rey, heredando el cargo de su hermano mayor. En la siguiente generación, Corbis era el mayor y Orsua el más joven. La secuencia genealógica es la siguiente indicándose entre paréntesis el orden de edad explícito en Livio:

${ }^{14}$ Polibio XXI 11, 6-8.

15 Cf. Livio XXXVII 25, 4. Sobre la institución del rey amicus, D. Braund, Rome and the Friendly King, Nueva York, 1984. F. W. Walbank, A Historical commentary on Polybius, vol. 3, Oxford, 1979, p. 103, sostiene que este «Andóbales» (= Indíbil) no es un verdadero rey, desconozco con qué fundamento, cuando los Escipiones lo presentan como tal y Polibio conoce las intenciones de los romanos.

${ }^{16}$ Livio XXVIII 21, 6-10.

${ }^{17}$ En Caro Baroja, op. cit., p. 198. 


\section{Padre de Corbis (1) Padre de Orsua (2) Corbis (3) \\ Orsua (4)}

Cabe presumir que ese orden de edad indica un orden de acceso a la realeza que opera con claridad en la generación de los padres, pero es fuente de conflicto en la de los hijos. Corbis aspiraría a la realeza dado que era el mayor de los herederos legítimos de su generación o clase de edad, Orsua lo haría invocando un eventual principio hereditario, sin duda discutible. El caso es que en vez de aceptar una especie de gobierno común, como el atestiguado en las otras parejas de hermanos dirigentes, prefieren dirimir el conflicto en duelo de acuerdo con una fórmula indoeuropea también institucionalizada y difundida por el área ibérica ${ }^{18}$.

\subsection{Otras parejas de reyes}

Con menos detalle conocemos otros casos análogos.

Tito Livio menciona a Meniacapto y Vismaro «dos famosos reyezuelos de los galos» ${ }^{19}$-entiéndase celtíberos-, que luchaban como aliados o mercenarios de los cartagineses cayendo en combates del año 212 a. de C. El historiador romano precisa que los despojos capturados, torques y brazaletes de oro, pertenecían sobre todo a estos galos. Tito Livio no menciona su eventual parentesco, pero sin duda forman una pareja de reyes.

Diodoro presenta una situación semejante. Cuenta que cuando el cartaginés Amílcar guerreaba en la península contra iberos y tartesios, luchó contra Istolacio, general de los celtas junto con su hermano ${ }^{20}$. El cartaginés consiguió matar a ambos junto con otros jefes destacados. Probablemente los hermanos encabezarían grupos celtas a sueldo de iberos y tartesios. Se trata entonces de hermanos, y aunque no se presentan como reyes, el cargo militar tal vez refleja la presencia de una institución de fondo como es, precisamente, la realeza.

Por último contamos con dos ejemplos más débiles, de épocas distintas.

Más cerca de la Segunda Guerra Púnica, horizonte cronológico de los casos examinados hasta aquí, está la composición de uno de los ejércitos de Viriato, comandado en el 141 a. de C. por dúo léstordroi llamados Curio y Apuleyo. Que Apiano, nuestra fuente, califique a los lusitanos como ladrones no sorprende. Deriva de la consideración de formas de guerra propia de los bárbaros que triunfa en testimo-

18 Véase F.J FernándeZ Nieto, «Una institución jurídica del mundo celtibérico», Estudios de Arqueología ibérica y romana. Homenaje a Enrique Pla Ballester, Valencia, 1992, pp. 381-4.

${ }^{19}$ Livio XXIV 42, 7-8: ... insignes reguli Gallorum.

${ }^{20}$ Diodoro XXV 10, 1-2. 
nios influidos por la ideología de la pax romana. Ahora nos interesa que estamos ante un doble comando militar, aunque carecemos de las precisiones institucionales o de parentesco que teníamos en otros casos ${ }^{21}$.

Mucho más lejos en el tiempo, y sirviendo un poco como bisagra para las situaciones altomedievales que examinaremos enseguida, está el caso de los caudillos hispanos Dídimo y Veriniano que defendieron los Pirineos de los ataques germanos entre los años 406 y 409. Eran hermanos, sobrinos de Teodosio el Grande y primos de Honorio y Arcadio, por tanto perfectamente integrados en la elite dirigente provincial que en esa época había alcanzado la cúspide del poder en Roma. Procedían de Cauca, en la actual provincia de Segovia, como toda la familia de Teodosio. Esto es, sus raíces estaban en plena área indoeuropea de la Península Ibérica. Por desgracia todo lo que de ellos sabemos tiene que ver con la situación político militar del Imperio en la época y nada permite observar en su acción conjunta un resto de «indigenismo», ni siquiera en el reclutamiento de un ejército privado. Por ello registramos este caso más por afán de ser exhaustivos que por pensar en la viabilidad de su integración en la serie hasta aquí establecida. Si algo hubiera que remitiese a este par al catálogo de jefes o reyes prerromanos hispanos sería por una hipotética perduración de la huella indoeuropea en su acción. Pero si tal hubo, nunca lo sabremos ${ }^{22}$.

\section{EL «ASOCIADO» DEL REY}

Estos casos de cogobierno solo son aparentes. En cuanto tenemos alguna precisión aparece una figura dominante, un orden jerárquico, una especialización funcional. Por ello considero posible avanzar la hipótesis de que esa forma de presentarse las cosas en las fuentes encubra una modalidad de sucesión a la realeza que se conoce con el nombre inglés dado a una antigua institución irlandesa, la tanistry. D. A. Binchy la describe como sigue:

«Una forma antigua de intentar evitar luchas internas en el seno de un linaje de reyes (con frecuencia un intento vano en la práctica) consistía en establecer el nombramiento de un sucesor en vida del rey en funciones. Esta era la institución conocida por los funcionarios y jueces ingleses con el nombre de 'tanistry'. La palabra irlan-

${ }^{21}$ Apiano $I b$. 68. Sobre el «bandolerismo» a ojos de los romanos de diferentes pueblos bárbaros véase M.V. García Quintela, Mitología y Mitos de la Hispania Prerromana III, Madrid 1999, pp. 6970, haciendo eco a trabajos de P. Briant.

22 C. Torres Rodríguez, «Paisajes escondidos de la historia de España. Heroicos defensores en el siglo V», Hispania 16, 1956, pp. 323-34, sistematiza los testimonios sobre los personajes en una perspectiva nacionalista un tanto rancia. 
desa tánaise significa habitualmente 'segundo, siguiente', pero en un artículo reciente el profesor D. Greene ha sugerido que en origen es un antiguo participio pasado 'esperado, ansiado', y que el tánaise ríg era el esperado para que sucediese al rey en funciones y de ello deriva el significado de 'segundo' o 'sucesor' ${ }^{23}$.

El tanist se nombraba con ocasión de la investidura del nuevo rey ${ }^{24}$. La razón para ello era la precariedad e incertidumbre que rodeaba la vida de cualquier rey irlandés, cuyas posibilidades de morir en batalla o asesinado eran muy altas, por lo que era necesario tener un sucesor disponible en todo momento. Esta práctica también explica, sigue D. A. Binchy, la razón por la que era raro que un hijo sucediese a su padre directamente, aunque puede muy bien aparecer en la lista de reyes tras uno o dos reinados. En el momento de la investidura del padre, el hijo sería demasiado joven para cumplir el cometido de tánaise ríg que tiene su propio 'grado' privilegiado en el rango de honores ${ }^{25}$. Por ello era más verosímil que se escogiese a un hermano, o tío, o primo del rey llegándose a algún tipo de acuerdo entre todos los aspirantes con una combinación de sistemas hereditarios y electivos ${ }^{26}$.

Recientemente otros autores han corregido esta interpretación mostrando que se debe desvincular la función del tánaise ríg de la del sucesor al trono. El primero sería, en efecto, el segundo del rey en funciones y su próximo colaborador, pero esa tarea no lo preseleccionaba como sucesor, que se elegía según otros procedimientos. Cada rey, por tanto, tendría su tánaise ríg y a su muerte se elegiría otra pareja formada por el nuevo rey y su correspondiente tánaise ríg ${ }^{27}$. Ahora bien, este importante matiz de interpretación no desmiente a D. A. Binchy sobre la frecuencia de la sucesión entre hermanos, que el mismo B. Jaski disecciona en diferentes situaciones ${ }^{28}$.

${ }^{23}$ D.A. BinChy, Celtic and Anglo-Saxon Kingship, Oxford, 1970, p. 26.

${ }^{24}$ E. Spenser, View of the state of Ireland (1592), citado por P. MCCANA, «The Topos of the Single Sandal in Irish Tradition», Celtica 10, 1973, pp. 160-6, p. 162; F.J. BYRNE, Irish Kings and HighKings, Londres, 1973, p. 38; B. JASKI, Early Irish Kingship and Succession, Dublín 2000, p. 272. Equivalentes hispanos de otros aspectos de la descripción de Spenser se estudian en M.V. GARCía Quintela, M. SAntos Estévez, «Petroglifos podomorfos de Galicia e investiduras reales célticas: estudio comparativo», AEspA 73, 2000, pp. 5-26.

${ }^{25}$ JASKI, op. cit., p. 248 reproduce el texto.

${ }^{26}$ BinCHY, op. cit., pp. 26-7.

${ }^{27}$ K. Simms, From Kings to Warlords. The Changing Political Structure of Gaelic Ireland in the Later Middle Ages, Woodbridge \& Wolfeboro, 1987, p. 56, tesis desarrollada por JASKI, op. cit., pp. 247-75; más detalles en T. M. CharLes-Edwards, Early Irish and Welsh Kinship, Oxford 1993, pp. 89-111, 217-18, y pp. 107-8 sobre la elección. Sobre ésta véase además SimMs, op. cit., pp. 42-4.

${ }^{28}$ JASKI, op. cit., pp. 130-40, 170, 191-9. Este uso sucesorio tiene un significativo efecto secundario: en las dinastías reales irlandesas siempre hay un gran número de individuos emparentados con un rey efectivo hasta una distancia de tres generaciones que constituyen la rígdamna, «material real», que es el grupo formado por los que tienen legitimidad dinástica para acceder al trono de acuerdo con las reglas establecidas, ibídem, pp. 171-90 y 232-247; y CHARLES-EDWARDS, op. cit., 101-10. 
Parece como si estos usos sucesorios de los pequeños reyes irlandeses altomedievales y su justificación fuesen un comentario del pasaje de Livio sobre el duelo entre Corbis y Orsua. Si éste aceptase la legitimidad de las aspiraciones de Corbis aparecería en una hipotética genealogía de los reyes de Ibes sucediendo a su padre, con el salto representado por el reinado de su primo, como ocurre en Irlanda con frecuencia. La presencia de parejas de reyes o generales en nuestros testimonios hispanos puede indicar, sugerimos, la presencia del rey en funciones junto con su rey «segundo» o «esperado», sea como colaborador en el ejercicio del cargo, sea como heredero legítimo, o como una combinación de ambas cosas ${ }^{29}$. Pero conviene, en todo caso, precisar mejor el sentido y límites de esta hipótesis pues la figura del «asociado del rey» aparece en otros lugares. Por ceñirnos a los de tradición indoeuropea podemos evocar dos casos.

En primer lugar, en las tablillas micénicas se distingue al rey, wanax, y al lawagetas, por que se atribuye a ambos una tierra que merece la calificación de temenos, fórmula que no aparece atribuida a la tierra de ningún otro individuo. Además, en la epopeya homérica, la tierra así calificada se entrega a personajes de rango real. Por ello se piensa que el lawagetas debe ser un segundo del rey o heredero. Pero en el mundo micénico carecemos de testimonios sobre las relaciones de parentesco entre los dos personajes, mientras que en la epopeya los temene se entregan contra la realización de un gran servicio o hazaña heroica por parte de quien lo recibe que puede no tener lazos de parentesco en el lugar en cuestión ${ }^{30}$.

También existe la figura del «asociado real» en la Roma de los reyes. Distintos testimonios presentan al sucesor como un patricio adulto que ejerce como magister equitum o tribunus celerum, funciones idénticas en el período monárquico. Este personaje también desempeña cargos sacerdotales en vida de su antecesor. El ejercicio de esas tareas le prepara para el acceso a la realeza sin que, obviamente, sea correcto hablar ni de diarquía ni de monarquía colegiada ${ }^{31}$. Pero en este caso P.-M.

${ }^{29}$ Una variante irlandesa es la del co-rey, lethrí, que aparece cuando una disputa por la sucesión se resuelve dividiendo el reino entre los dos hermanos, JASKI, op. cit., pp. 212 y 242 y véase infra el caso n. $^{\circ} 10$ del apéndice 2 de este trabajo.

${ }^{30}$ P. CARLIER, La royauté en Grèce avant Alexandre, Estrasburgo, 1984, pp. 62-3, 102-7, 158-60, que destaca por su exposición y análisis de las fuentes. Más recientes, P. REHAK, «Enthroned figures and the function of the mycenaean megaron», Aegeum 11, 1995, 95-117, sobre los megara dobles de los palacios micénicos véase pp. 96, 100-1, y su conclusión que resalta la existencia de una noción de soberanía femenina, pp. 113-7; T.G. PALAIMA, «The nature of the Mycenaean wanax: non-indo-european origins and priestly functions», Aegeum 11, 1995, pp. 119-41, pp. 129-34, sobre la relación wanax-lawagetas.

${ }^{31}$ Que, sin embargo, no deja de aparecer de manera un tanto furtiva en la gemelidad efímera de Rómulo y Remo y en la colegialidad del ejercicio real entre Rómulo y Tito Tacio, véase D. Briquel, «Perspectives comparatives sur la tradition relative à la disparition de Romulus», Latomus 36, 1977, 
Martin ha podido identificar un principio sucesorio claro descrito como una «sucesión exogámica en línea uterina» consistente en que son candidatos a la realeza todos los varones relacionados con el rey en funciones a través de mujeres pudiendo existir procedimientos electivos entre aquellos varones que cumplen la regla sucesoria $^{32}$. Es probable, además, que este principio haya sido actualizado de alguna forma por César y Augusto ${ }^{33}$.

\section{ASOCIADOS Y HERMANOS DE REYES ALTOMEDIEVALES}

Más cercanos, en la propia Hispania, cabe considerar usos sucesorios de la monarquía astur-leonesa y de la segunda dinastía de reyes de Pamplona.

\subsection{La dinastía astur-leonesa}

Con respecto a la monarquía astur-leonesa C. Sánchez Albornoz no habla de la existencia de la institución de los «asociados al rey», pero la idea se desprende de algún pasaje. Su propuesta básica consiste en defender la pervivencia en la monarquía astur-leonesa del principio electivo, vigente en la monarquía visigoda, y cómo solo de forma paulatina y relativamente tardía se asentó el principio hereditario en esa dinastía. Su argumento se apoya en afirmaciones formales de las fuentes ${ }^{34}$, pero tropieza con las evidentes relaciones de parentesco entre todos los ocupantes de la realeza. Justifica esta situación con dos argumentos. En primer lugar, indica que el prestigio de los primeros reyes se hizo extensivo a sus familias haciendo de sus miembros candidatos «naturales», por así decirlo, a la elección. En segundo lugar, constata que los electores son los miembros de la corte «hechura de la estirpe alfonsina» por lo que su opción por un miembro de la familia reinante sería obvia ${ }^{35}$.

Contraria a esta tesis «goticista» es la tesis «autoctonista» defendida por A. Barbero y M. Vigil. Estos autores analizan con detalle las fuentes mostrando la primacía temporal de las versiones que subrayan el elemento local en la sucesión, y la

pp. 253-82. No podemos entrar aquí en el tema del consulado romano y los rasgos que presenta esa institución de herencia de los antiguos reyes.

32 P.-M. MARTIN, L'Idée de royauté à Rome, 1 . De la Rome royale au consensus républicain, Clermont-Ferrand 1982, pp. 19-40, 55-67.

${ }^{33}$ P.-M. MARTin, L'Idée de royauté à Rome, 2. Haine de la royauté et séductions monarchiques: (du IVe siècle av. J.-C. au principat augustéen), Clermont-Ferrand 1994, pp. 374-6, 471-3.

${ }^{34}$ Por ejemplo, C. SÁnCHEZ Albornoz, Viejos y nuevos estudios sobre las Instituciones medievales españolas: 2da ed. ampliada, vol. II, Instituciones económicas y fiscales, Instituciones JurídicoPolíticas, Madrid 1976, p. 1115 n. 41.

35 Ibídem, pp. 1114-5. 
realeza en general, contra el carácter derivado, segundo e ideológico, de las versiones que inciden en la herencia visigótica. Destacan en su investigación la existencia de un horizonte documental que solo puede explicarse por la presencia de intereses y tradiciones puramente locales a las que conceden mayor credibilidad. Hacen hincapié, sobre todo, en el significativo papel que desempeñan toda una serie de mujeres de la familia real en la elección de los sucesores de los reyes.

Esto se constata cuando Ermesinda, hija de Pelayo, Audosinda, hija de Alfonso I, y una hija anónima de Fruela, parecen determinar el ascenso al trono de sus respectivos maridos -Alfonso I, Silo y Nepociano, respectivamente. Sin embargo, señalan la ausencia de esta relación en ramas colaterales descendientes de Pedro de Cantabria. Terminan definiendo el sistema detectado como una «sucesión matrilineal indirecta ... que iría desapareciendo hasta imponerse la línea patrilineal que coexistió alternándose con la línea matrilineal» ${ }^{36}$. Finalmente buscan la raíz de esta costumbre sucesoria en usos prerromanos donde destaca el papel de la filiación matrilineal o de formas de avunculado en las dedicatorias funerarias latinas con importantes rasgos de indigenismo en sus fórmulas ${ }^{37}$.

Cada propuesta hace hincapié en datos diferentes que no son necesariamente contradictorios. La elegibilidad de tradición gótica -o germánica en general ${ }^{38}$ - y el papel de las mujeres en la sucesión que puede derivar de una tradición autóctona.

Es muy difícil decir que ambas son ciertas, o verdad, dada la naturaleza de la documentación y los sesgos ideológicos que pesan sobre ella. Digamos, con más prudencia y de cara a avanzar otra hipótesis, que ambas son verosímiles. De forma general, es erróneo plantear para esta clase de monarquías «antiguas», por llamarlas de alguna forma, la alternativa entre principio dinástico y elección, pues ambos principios conviven sin problemas o, mejor dicho, con un tipo de problemas integrado en el propio sistema en otros lugares ${ }^{39}$.

Ambos principios coexisten en la Roma de los reyes, citada más arriba. A. Barbero y M. Vigil ya habían apuntado la semejanza ${ }^{40}$, pero limitan la pertinencia de

36 A. Barbero, M. Vigil, La Formación del feudalismo en la Península Ibérica, Barcelona 1978, pp. 327-30.

37 Ibídem, pp. 331-2. Véase una pertinente matización a esta reconstrucción evolucionista o diacrónica en F. DELPECH, «Fragments hispaniques d'un discours incestueux», en A. REDONDO, ed., Autour des Parentés en Espagne aux XVIe et XVIIe siècles. Histoire, Mythe et Littérature, París, 1987, pp. 77-128, en pp. 112-18.

38 Tácito Historias IV 15, 2; Gregorio de Tours Historia de los francos II 40; Saxo Gramático, Gesta Danorum I 2, 1.

39 Véase para Irlanda supra n. 27. En sentido análogo W.A. CHANEY, The Cult of Kingship in Anglo-Saxon England, Manchester, 1970, p. 17 y n. 35.

40 Barbero, Vigil, Formación, op. cit., pp. 330-4. 
la comparación al descartar los rasgos de elegibilidad presentes en Roma. Por otra parte su noción de «sucesión matrililineal indirecta» es menos precisa y explicativa que la noción de «sucesión exogámica en línea uterina» empleada por P.-M. Martin que, por lo demás, bien puede servir para los casos astur-leoneses considerados. Pero tienen razón estos autores al señalar la debilidad del argumento de C. Sánchez Albornoz cuando expone las razones por las que la elección se efectuaba siempre en el seno de la misma familia, pues parece fuera de dudas que la realeza circula entre los integrantes de un determinado linaje real. Otra cosa es desentrañar los mecanismos por los que se produce la sucesión en tal linaje, pues parece claro que el principio hereditario no es norma hasta relativamente tarde. Incluso hasta más tarde de lo que señalan A. Barbero y M. Vigil, que detienen su investigación con Alfonso III. Al resaltar la transmisión de la herencia por vía femenina A. Barbero y M. Vigil ponen de relieve una modalidad que actúa en sólo tres de los trece casos que estudian; aunque es cierto que los consideran restos de un sistema en retroceso ante el paulatino triunfo del régimen patrilineal.

\section{CRITERIOS SUCESORIOS DE LOS REYES ASTUR-LEONESES:}

1 Elección. - 2 Asociación. - 3 Vía femenina. - 4 HeREDEROS DIRECTOS DE PADRES

\begin{tabular}{|c|l|}
\hline Generaciones & \multicolumn{1}{|c|}{ Reyes } \\
\hline 1 & 1. Pelayo \\
\hline 2 & 2. FAVILA 3. Alfonso I \\
\hline 3 & 4. FrUELA I 5. Aurelio 6. Silo 7. Mauregato 8. Bermudo I \\
\hline 4 & 9. Alfonso II 10. Nepociano 11. Ramiro I \\
\hline 5 & 12. ORDOÑo I \\
\hline 6 & 13. AlFonso III \\
\hline 7 & 14. ORDOÑo II 15. Fruela II \\
\hline 8 & 16. Alfonso IV 17. Ramiro II \\
\hline 9 & 18. ORDOÑO III 19. Ordoño IV \\
\hline 10 & 20. Ramiro III 21. Bermudo II \\
\hline 11 & 22. Alfonso V \\
\hline
\end{tabular}

Creo que se explica mejor el sistema sucesorio si, guiados por los testimonios antiguos de reyes hermanos hispanos y las situaciones de asociación real evocadas, consideramos de forma global a la totalidad de los miembros de cada generación 
del linaje real (véase la tabla adjunta y la genealogía $n .^{\circ} 1$ ). De esta forma podemos apreciar cómo la realeza pasa por todos los miembros disponibles de cada una de las generaciones dentro del linaje, contando parientes colaterales y por alianza (este es el papel de las mujeres), antes de pasar a la siguiente. Favila y Alfonso pertenecen a la misma generación, y en la siguiente contamos hasta cinco reyes. Destaca, además, el retraso en el ascenso al trono de Alfonso II, asociado por Audosinda y Silo con la función de comes palatinum, pero relegado por su tíos Mauregato y Bermudo I, que lo asoció por segunda vez al nombrarlo heredero en vida. Con Alfonso II comienza la cuarta generación formada por tres reyes. El principio hereditario se impone durante más de medio siglo para volver, seguidamente, al sistema antiguo. A Ordoño II le sucede su hermano, a quien sucede su sobrino Alfonso IV, sucedido por su hermano Ramiro II. Ordoño III y Ordoño IV y Bermudo II y Ramiro III siguen la norma en las dos generaciones siguientes.

$\mathrm{La}$ «asociación» al trono sólo aparece de forma expresa las dos veces en que el beneficiado es Alfonso II. Pero la primera supondría, de hecho, un ataque a la norma que intentamos sacar a la luz pues todavía había candidatos de la generación anterior aptos para la realeza. Sin embargo Bermudo I aplica la norma correctamente al asociar a Alfonso II con preferencia sobre su propio hijo, seguramente mucho más joven entre los varones de su generación. Nepociano también se prepara para el ejercicio de la realeza ocupando el puesto de comes palatii con el que años atrás Adosinda y Silo habían preparado la candidatura de Alfonso II. Que este era un cargo trampolín para el acceso a la realeza lo atestigua que otros comes palatii, Aldroito y Piniolo, disputasen la realeza a Ramiro I, aunque ignoramos qué otros derechos podrían invocar. Por último, en la primera generación, la explicación de que Alfonso luchó junto con su suegro, aunque no supone una asociación formal, sin duda lo preparaba para el acceso a la realeza.

Obviamente el sistema genera los conflictos de los que están plagadas las crónicas cuando entre los derechohabientes de cada generación se combinan ambiciones, diferencias de edad que pueden ser notables, capacidades intelectuales o militares, popularidad ... Vimara es asesinado por su hermano «ob invidiam regni», Mauregato es presentado como tirano por imponer la regla monástica a su sobrino Alfonso II, al que destierra pero no mata. Nepociano termina cegado por orden de Ramiro I ${ }^{41}$. Los hijos de Ordoño II se enfrentan por el trono con los de Fruela II ... La conflictividad es un elemento estructural de este sistema sucesorio, no la excepción, ni un indicio de su mal funcionamiento. Es así, simplemente.

${ }^{41}$ El cegamiento de un competidor era frecuente entre los aspirantes irlandeses a la realeza, el agredido quedaba descalificado y el tratamiento era menos radical que el asesinato, JASKI, op. cit., p. 86 y n. 125 con fuentes y bibliografía, cf. SimMs, op. cit., pp. 50-1. 
GENEALOGÍA 1: Reyes Astur-leoneses. Las líneas parabólicas indican formas de asociación y las fórmulas empleadas.

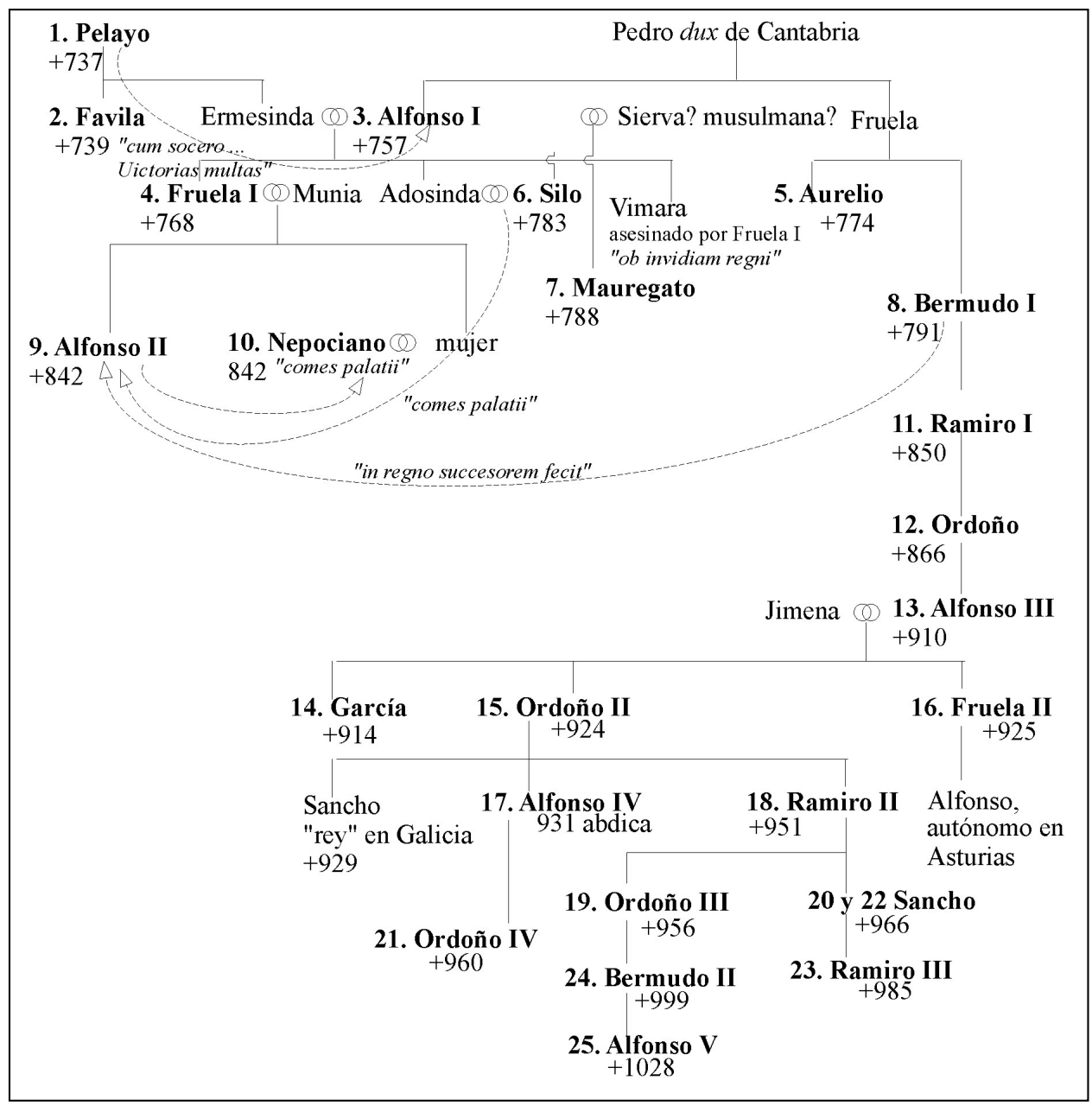

En resumen, el sistema sucesorio de la monarquía astur-leonesa parte de un linaje real en el que los parientes por alianza figuran con derechos propios. Dentro de esa familia real se elige (por parte de quienes pueden hacerlo) al rey de entre los miembros de la misma generación no pasándose a la siguiente hasta agotar la anterior. En este sistema la «asociación» con el rey en ejercicio puede favorecer a un candidato (Alfonso I, Alfonso II en la segunda ocasión) pero no forzosamente (Alfonso II la primera vez, Nepociano). 
Es cierto que en nuestras fuentes asturleonesas sobre la realeza no aparecen fórmulas como las irlandesas tánaise ríg, para identificar al segundo o asociado al trono, o rígdamna, para identificar a un grupo de parientes todos ellos aspirantes legítimos a la sucesión. Sin embargo parece que en este sistema se aprecian situaciones institucionales muy semejantes: conocemos asociados a los reyes y observamos cómo se forma un grupo de aspirantes a la realeza entre los parientes de la misma generación. Un testimonio comparativo procedente de la antigua Tesalia nos lleva a pensar que no nos hallamos ante una simple analogía: allí se conoce una «clase» de reyes, basileeis, de donde proceden los reyes efectivos, con un modo de funcionamiento semejante a la rígdamna irlandesa dentro de los límites de nuestro conocimiento de ambas instituciones ${ }^{42}$.

\subsection{La segunda dinastía de Pamplona}

Si la dinastía astur-leonesa ofrece la cara conflictiva de este sistema sucesorio, la segunda dinastía de reyes de Pamplona presenta su aspecto armonioso porque, sostenemos, el sistema sucesorio pamplonés tiene una estructura muy parecida a la del que acabamos de examinar.

Los rasgos que nos interesan se aprecian sobre todo en la segunda dinastía de Pamplona, formada por los reyes Jimenos que dominan todo el siglo X. Acceden al poder, de forma casi inevitable, cuando tres de los hijos de García Jiménez se unen en matrimonio con otras tantas mujeres de la familia de los Aristas, linaje que ocupaba la realeza hasta entonces, y su hija Sancha Garcés también se casa con un varón Arista (véase genealogía 2). Así Sancho Garcés cuando accede al trono de Pamplona en el año 905 es un pariente por alianza de la casa real exactamente como en Asturias lo había sido Alfonso I con respecto a Pelayo. Por otra parte, la reiteración de la alianza, hasta cuatro casos en la misma posición estructural, indica una especie de dumping por la realeza de los Jimenos sobre los Aristas. Con tres opciones posibles era fácil que uno de los hermanos Jimenos heredase, pese a muertes prematuras u otros incidentes.

Que esto no es fruto de la casualidad se aprecia si consideramos los matrimonios, otra vez masivos, pues son tres casos, de los hijos de Íñigo Garcés, hermano de Sancho Garcés, con mujeres del linaje muladí de los Ibn Qusa. De esta forma los Jimenos suplantan e invierten una alianza que en generaciones anteriores habían protagonizado mujeres Aristas con varones Ibn Qusa. Por otra parte, sabemos de enfrentamientos entre los hermanos Íñigo y Sancho y que Sancho (y sobre todo su mujer, Toda, a la que las fuentes atribuyen un gran protagonismo) casa a sus hijas

${ }^{42}$ B. Helly, L'état Thessalien, Aleuas Le Roux les Tétrades et les tagoi, Lyon, 1995, p. 126. 
con varones de la dinastía astur-leonesa ${ }^{43}$. Es decir, los enfrentados se buscan parientes por alianza en dos frentes distintos, antaño ocupados por los Aristas que quedan totalmente desplazados. La reiteración de matrimonios de hermanos en la misma dirección indica que ante una eventual desaparición prematura siempre quedaba otro hermano para cubrir su función en la política dinástica del linaje.

GENEALOGÍA 2: De los Arista a los Jimeno de Pamplona.

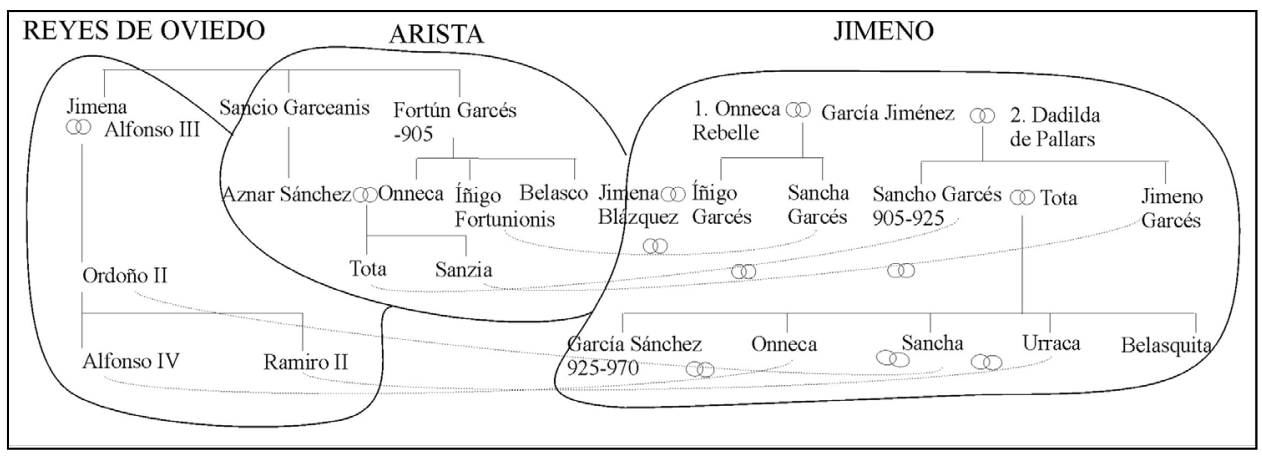

La equivalencia estructural entre los hermanos aparece reiteradamente a lo largo del gobierno de la dinastía de los Jimenos en el siglo X. En primer lugar Jimeno Garcés sucede a su hermano Sancho Garcés el año $925^{44}$. Esta situación se reitera a través del lugar especial ocupado por la dinastía de los reyes de Viguera (marca militar riojana en el valle del Iregua que protegía Pamplona contra los ataques musulmanes). En efecto, los hermanastros Sancho Garcés II y Ramiro de Viguera reciben simultáneamente el título de rex (véase genealogía 3). Aunque se indica la primacía de $\mathrm{Sancho}^{45}$ el título indica la equivalencia funcional entre ambos. En este

${ }^{43}$ Véase C. SÁnCheZ Albornoz, Orígenes del Reino de Pamplona: su vinculación con el Valle del Ebro, Pamplona, 1981, p. 93 y toda la primera parte del libro; J.M. LACARRA, Historia política del Reino de Navarra. Desde sus orígenes hasta su incorporación a Castilla, vol. I, Pamplona, 1972, pp. 15-178, cuestiones dinásticas en pp. 41, 57, 79-90, 102-5, 132, 144, 164-5, 168.

44 A. Ubieto ARTETA, «Monarcas Navarros Olvidados. Los reyes de Viguera», Hispania 10, 38, 1950, pp. 3-24, p. 10, sostiene que lo hizo como regente de su sobrino García Sánchez, pero los documentos que cita en la n. 19 lo califican indudablemente como rey.

45 ... et sub illius impero frater eius Ranimiro in Vekaria et in Leza, Crónica de Albelda citada por A. Isla Frez, Realezas hispánicas del año mil, Sada, 1999, p. 122 (= UBIETo, art. cit., p. 14). Véase el 
GENEALOGÍA 3: los Jimeno de Pamplona. Genealogía adaptada de los estudios de Sánchez Albornoz, Ubieto y Lacarra. En negrita los reyes de Pamplona numerados según el orden de acceso al trono. Los números seguidos por letras indican a los parientes de la generación del rey en funciones que reciben el título de rex o derivado.

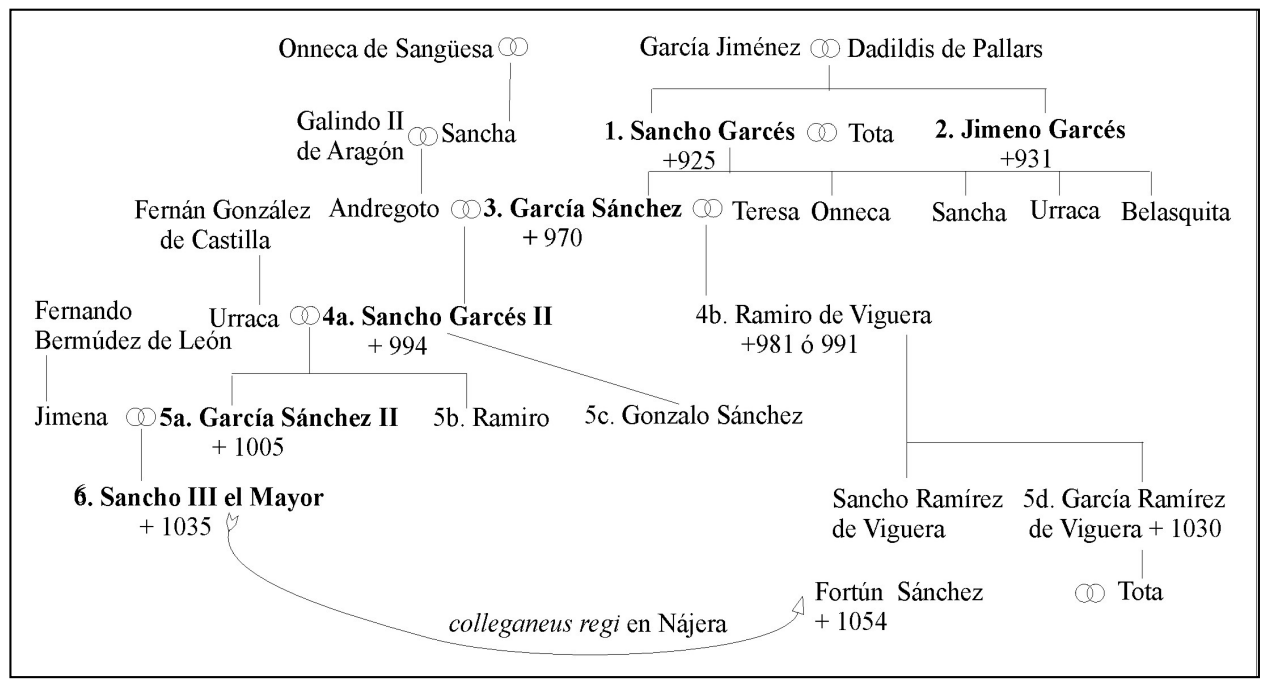

caso Ramiro falleció antes que su hermano, pero sin duda sería un candidato a la realeza si el futuro García Sánchez II tuviese algún tipo de problemas (del mismo modo que Jimeno Garcés había heredado a su hermano dos generaciones antes).

En la generación de García Sánchez II, su hermano Ramiro y su hermanastro Gonzalo reciben el título de regulus, que indica su rango inferior, y sus primos Sancho Ramírez y García Ramírez el de regnante rex o rex que heredan de su padre. Sancho se limita a utilizarlo cuando actúa sólo ${ }^{46}$, y García recibe el título de rex en dos testimonios ${ }^{47}$. También parecen claras las opciones a la realeza de estos individuos en caso de alguna falla en el orden hereditario que triunfa en el linaje. De hecho, en la reconstrucción propuesta por A. Ubieto, la muerte del primogénito Sancho despeja el camino para que García reciba el título de rex. Una generación más

comentario de LACARRA, op. cit., p. 165 y de UBIETO, art. cit. pp. 13-14 con una hipótesis sobre las condiciones institucionales bajo las que produce esta cesión. No pretendo cuestionar esta y otras apreciaciones de los medievalistas. Intento tomarme en serio el título de rex e interpretar su sentido institucional en un sistema de parentesco determinado y contemplado desde un punto de vista estructural. Las intrigas de corte y otros temas presentes en los testimonios y desmenuzados y explicados por los medievalistas son la forma en que se vive esa estructura, sin negar su existencia, y a sus trabajos remito.

${ }^{46}$ ISLA FREZ, op. cit., pp. 122-4.

${ }^{47}$ UBieto, art. cit., p. 19. 
tarde reaparece la relación, una de las hijas de García, Tota, se casa con Fortún Sánchez de Nájera (cerca de Viguera) que recibe de Sancho III el Mayor el título de colleganeus regi ${ }^{48}$. Esta expresión es una buena fórmula para indicar una «asociación real» y también resulta significativo que se obtenga por vía femenina. Parece indudable que el sistema dinástico pamplonés exige la disponibilidad de un cierto número de candidatos a la realeza de la misma generación que el rey efectivo hasta bien entrado el siglo XI. Que además estos personajes ejerciesen una función militar en un territorio estratégico los califica todavía más, si cabe, para esa candidatura.

Si ahora comparamos el sistema sucesorio astur-leonés con el pamplonés destacan importantes semejanzas. En primer lugar el relieve de los parientes por alianza: es por esta vía que los Jimenos se convierten en el linaje real y que Fortún Sánchez es asociado por Sancho el Mayor. En segundo lugar la equivalencia estructural entre los miembros del linaje de la misma generación se subraya de dos formas: mediante los matrimonios reiterados de hermanos-as en la misma dirección y mediante el título real compartido por hermanos, hermanastros, primos o parientes por alianza.

¿Son estos reges o regulus, reyes «asociados»? Quizás por extensión quepa utilizar el término pues de hecho gobiernan determinados territorios subordinados, aunque ninguno de ellos ocupa el trono principal. Recordemos, por otro lado, que en el caso astur-leonés la «asociación» no era suficiente para acceder al trono en la primera tentativa de Alfonso II y en el caso de Nepociano.

Pero hay diferencias. La primera es básica: en Pamplona no hay trazas de elección y quizás este rasgo es el que incide en la mayor estabilidad comparativa del sistema sucesorio navarro. La segunda deriva de la anterior: triunfa el principio hereditario. Pero en este triunfo tal vez no se deba ver tanto un rasgo del sistema como el resultado de una coyuntura concreta: sucede que los reyes (con la excepción de Sancho Garcés I) siempre tuvieron a su disposición herederos en buenas condiciones en el momento necesario. De no ser así entraban en línea sucesoria los miembros del linaje real de su misma generación.

Por otra parte, no creo que la atribución del título de rex a los «asociados», aunque se indique su subordinación, deba ser minusvalorada. En primer lugar, porque permitía un ejercicio efectivo de parcelas de poder importantes en la monarquía de Pamplona; en segundo término, porque revestía un aura simbólica significativa, como atestigua la iconografía ${ }^{49}$; por último, porque el título, como tal, merece una

\footnotetext{
48 Ibídem, p. 22.

${ }^{49}$ Véase infra y, otros testimonios en ibídem, pp. 15-6 donde Sancho Garcés II, su esposa Urraca y Ramiro firman conjuntamente o aparecen mencionados como reges y regina.
} 
consideración institucional mayor que la acostumbrada entre los historiadores centrados en la descripción del proceso político de la monarquía pamplonesa. También en este caso desconocemos términos como tánais ríg o rígdamna, pero la situación institucional, si consideramos a todos los reges de cada generación, está presente y el paralelo de los basileeis de Tesalia, evocado más arriba, también ha de considerarse en este caso.

\section{ASPECTOS DE EXPLICACIÓN GENÉTICA}

La riqueza de la documentación medieval, pese a las dudas y lagunas que deja, es mucho mayor que la disponible para nuestros reyes peninsulares de la Segunda Guerra Púnica. Pero no se puede dejar de señalar la profunda analogía existente entre los dos casos antiguos sobre los que tenemos mayor información y los dos casos medievales examinados.

Los hermanos ilergetes Indíbil y Mandonio ocupan una posición casi igual, aunque siempre aparece destacado Indíbil. Podría considerárseles teniendo en cuenta simplemente su posición relativa ante la realeza, como los equivalentes antiguos de las situaciones detectadas entre los Jimenos navarros. Los primos Corbis y Orsua luchan por una realeza que entre sus padres se había sucedido de forma pacífica y legítima y ambos, a su vez, se consideraban con derecho pleno a ocuparla. Serían, por lo tanto, los equivalentes antiguos de tantas situaciones de inestabilidad sucesoria que se aprecian en el linaje de reyes astur-leonés. ¿Es posible englobar bajo un término general estas situaciones?

Una primera serie de posibilidades parte de la explicación genética. En este sentido cabría buscar, en primera instancia, hacia un uso indoeuropeo, sin mayor precisión. Pero en el caso romano nada indica algún grado de equivalencia estructural entre los individuos de la misma generación que el rey en funciones. La apelación a Roma como contraprueba es significativa ya que es bien conocido el peso que la herencia indoeuropea tuvo en las concepciones romanas de la realeza ${ }^{50}$. Tampoco en el mundo griego aparece nada tan claro. Por ello si la equivalencia estructural entre los integrantes de una generación es un rasgo determinante en los cuatro casos hispánicos que hemos examinado, tanto en su versión conflictiva como en su versión pacífica, parece que debemos buscar en otra dirección.

\footnotetext{
${ }^{50}$ Resumen esclarecedor en D. BRIQUEL, «À propos de Tite-Live, I: l'apport de la comparaison indo-européenne et ses limites», REL 76, 1998, pp. 41-70.
} 
GENEALOGÍA 4: El linaje de Conailli Muirtheimne. Según Byrne, Irish Kings and High Kings, p. 123; ejemplos equivalentes en p. 280, 286, 289, 297, 300 y 301. Reyes en negrita. Los números indican el orden sucesorio. Los saltos en la numeración corresponden a reyes de genealogía desconocida.

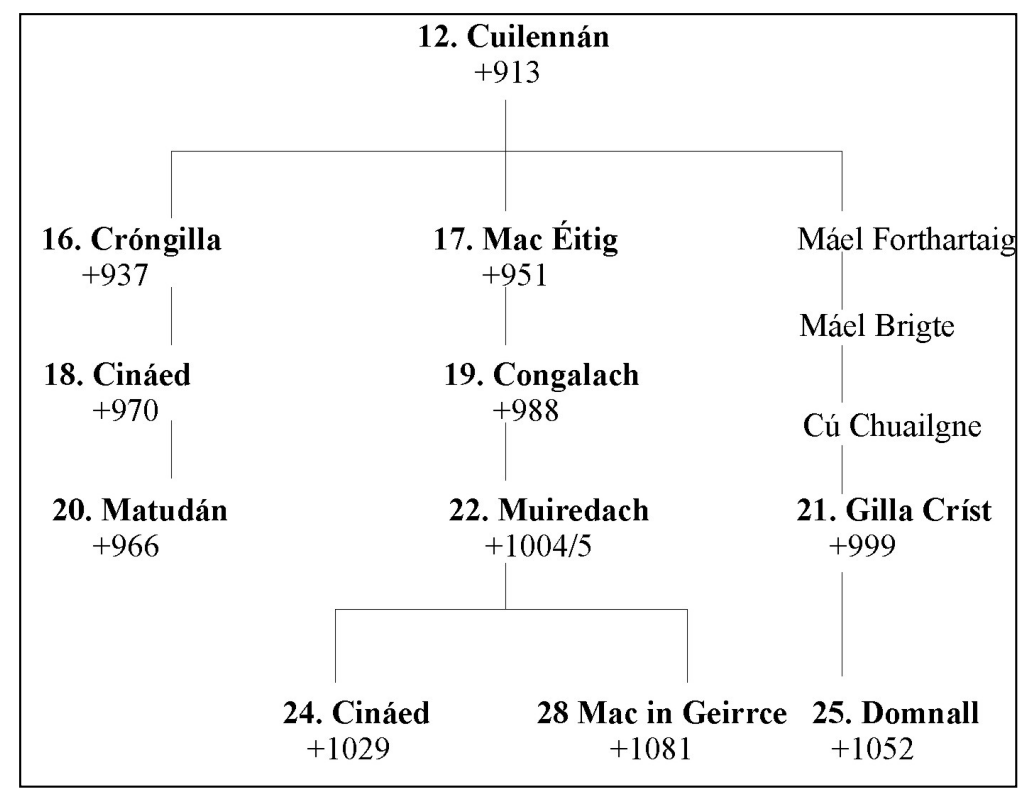

El ejemplo irlandés vuelve a resultar significativo. Ello se debe a las peculiaridades de su sistema político anterior a la feudalización. En esa época la isla se dividía en centenas de tuath o pequeños reinos sobre los cuales contamos con crónicas más o menos pormenorizadas. Ello permite reconstruir las genealogías de un buen número de linajes reales para épocas similares a las que hemos considerado en la Alta Edad Media hispana ${ }^{51}$. Pues bien, en esas sucesiones de reyes se observa cómo la realeza circula en muchas ocasiones entre los miembros de una generación, hermanos o colaterales, antes de pasar a los de la siguiente (véase la genealogía 4, pero los ejemplos podrían multiplicarse). También son proverbiales las querellas, luchas, asesinatos que tiñen las crónicas de los reyes de Irlanda. Otros aspectos significativos son la existencia de procedimientos de elección restringida entre los miembros del linaje real y la institución del «asociado» o tanaise del que ya hemos hablado 52 .

${ }^{51}$ BYRNE, op. cit., recoge los árboles genealógicos de 21 dinastías reales que agrupan a unos 350 reyes de distintas categorías entre otros personajes de sus familias, pp. 280-301; JASKI, op. cit., pp. 301-16, presenta 12 tablas genealógicas en apéndice y alguna más en el texto.

${ }^{52}$ En trabajos recientes, algunos en colaboración con M. Santos Estévez, he utilizado aspectos de 
La diferencia entre lo visto en la Roma de los reyes y los casos hispanos analizados, junto con la semejanza entre lo que hemos analizado en la Península con respecto a algunos de los rasgos de la realeza irlandesa nos inducen a precisar esta primera hipótesis. No estaríamos, entonces, ante un más genérico uso indoeuropeo sino ante un culturalmente más preciso uso céltico. Pero, a su vez, esta hipótesis plantea problemas, pues es discutible la pertenencia de los testimonios que hemos examinado a las áreas célticas.

\subsection{Aspectos de tradición céltica}

Para empezar, los ilergetes no figuran entre los pueblos célticos de la antigüedad hispana. Tampoco sabemos la adscripción cultural de la ciudad de Ibes dado que no es segura su localización, aunque A. Holder señala el carácter céltico de los nombres de Corbis y Orsua ${ }^{53}$. Pero la ciudad puede ser la alicantina Ibi, como sugieren otros, y por tanto situarse fuera del área céltica peninsular. En ambos casos la presencia de rasgos célticos podrían deberse a fenómenos de imitación institucional o de expansión. Cabe recordar los testimonios en los que se nos habla de jefes militares celtas operando en territorio ibérico ¿No podrían en algunos casos hacerse con el poder en un lugar en donde tuviesen fuerza suficiente o no recibiesen la soldada prometida? Los maryannu, grupos de guerreros indoeuropeos que operan en medios semíticos en el Oriente Medio del Segundo Milenio, actúan así cuando se presenta la ocasión. Pasemos a la Edad Media.

Podemos considerar dos opciones sobre la dinastía astur-leonesa. En primer lugar el referente germánico, «goticista», destacado por Sánchez Albornoz. En segundo lugar el aspecto «autoctonista» puesto de relieve por A. Barbero y M. Vigil. Si es este segundo modelo el que impera, el recurso a la filiación céltica de la población astur en la antigüedad prerromana no ofrece problemas ${ }^{54}$. Pero hay

la realeza irlandesa para esclarecer testimonios arqueológicos, institucionales, míticos, folclóricos o iconográficos, de la Península Ibérica en épocas diferentes, GARCía Quintela, SANTos EstéVEZ, «Petroglifos podomorfos», art. cit.; ID., ID., «Petroglifos podomorfos del Noroeste Peninsular: nuevas comparaciones e interpretaciones», Revista de Ciências Históricas, 15, 2000, pp. 7-40; M.V. GARCía QuINTELA, «Le programme d'accès à la royauté dans le monde celtique: pour une anthropologie politique celtique», Études celtiques, 2002, en prensa; ID., El reyezuelo, el cuervo y el dios céltico Lug: aspectos del dossier ibérico, Bruselas, 2005.

${ }^{53}$ A. HoLDER, Alt-Celtischer Sprachschatz, Leipzig 1896-1907, Corbis, vol. 1, col. 1117; Orsua, vol. 2, col. 879 .

${ }^{54}$ En el libro de F. Lomas Salmonte, Asturia prerromana y Altoimperial, Sevilla 1975, p. 39, el tema estaba fuera de discusión apoyándose el los trabajos de M. ${ }^{a}$ L. Albertos y R. Palomar Lapesa. Aportaciones recientes insisten en el tema desde otros ángulos, F. MARCO SIMÓN, «Heroización y tránsito acuático: sobre las diademas de Mones (Piloña, Asturias)» en J. MANGas, J. Alvar (eds), Home- 
más, la crítica que efectúan A. Barbero y M. Vigil a los testimonios sobre la elección de los reyes astures como reflejo de un modelo ideológico importado, «goticista», para buscar la legitimidad de la naciente monarquía astur no se impone. La elección del rey es tan céltica como germánica y es un rasgo que, al menos sobre el papel, puede ser tan autóctono en Asturias como la función de las mujeres en la sucesión que ponen de relieve ${ }^{55}$, de hecho estos autores aceptan sin problemas como locales los testimonios sobre la elección de Pelayo ${ }^{56}$. Otra cosa es que nuestras fuentes presenten estos hechos bajo un prisma «goticista» buscado por los reyes como forma de legitimación de su poder dinástico.

Por último, los vascones (y recordemos que los Jimenos lo eran) figuran entre los pueblos más conservadores del solar ibérico, pero no viven en una urna de cris-

naje a José M. Blázquez, vol. II, Madrid 1994, pp. 319-348; L. Sagredo, L. Hernández Guerra, «Los testimonios epigráficos de LVG en Hispania», Memorias de Historia Antigua 17, 1996, pp. 179201, véase el significativo mapa de la p. 191, que atestigua la presencia de Lug entre los astures. M. ${ }^{a}$ C. GonzÁlez Rodríguez, Los Astures y los Cántabros Vadinienses, Vitoria 1997, p. 47 n. 103; 59, 64 n. 148, pasa de puntillas sobre la cuestión. Me parece que la crítica de I. SASTRE PRATS, Las formaciones sociales rurales de la Asturia Prerromana, Madrid 2001, pp. 78-93, a quienes interpretan las sociedades de la Edad del Hierro en el Noroeste peninsular con ayuda de paralelos célticos apunta a algo que difícilmente pueden hacer: no construir una adecuada explicación de la evolución social del mundo castreño. Un simple detalle, la ideología céltica (como tal ideología) ignora olímpicamente cuestiones agrarias cuando es evidente el peso fundamental de la base campesina de las sociedades citadas, cosa que la propia Inés Sastre pone muy acertadamente de relieve en su libro. Ha de reconocerse que estamos ante haces de realidad diferentes que se interpretan de acuerdo con métodos de análisis histórico específico. En este sentido, lo mismo que las comparaciones indoeuropeas difícilmente pueden explicar la evolución de una sociedad, tampoco las teorías arqueológicas, basadas en el estudio del registro material, pueden dar cuenta de determinados aspectos ideológicos de esas sociedades.

55 A los testimonios de interpretación difícil destacados por estos autores procedentes de las inscripciones vadinienses, donde pesan las relaciones matrilineales (véase A. BARBERO, M. VIGIL, Sobre los orígenes sociales de la reconquista, Barcelona, 1974, pp. 158-182, y puntualizaciones críticas en GonZÁlez RodríGUEZ, op. cit., pp. 118-9 y SASTRE Prats, op. cit., pp. 243-259), cabe añadir testimonios literarios fragmentarios relativos a diferentes áreas del noroeste peninsular en sentido extenso (y por tanto al área céltica de la península prerromana), que reflejan un papel relevante de la mujer en las relaciones matrimoniales. Estrabón III 4, 18, refiriéndose a los cántabros, indica que los hombres dotaban a las mujeres que, a su vez, buscaban esposas para sus hermanos. Catón (en Prisciano VII, p. 293 H) se refiere a una situación peninsular en general y afirma que los hombres no dotaban a sus hijas. Salustio Hist. 91, sostiene aludiendo a los celtíberos, que las mujeres escogían a sus consortes por el valor manifestado en el combate (bien estudiado por G. SoPEÑa GÉnzor, Ética y Ritual: Aproximación a la comprensión de la religiosidad de los Celtíberos, Zaragoza 1995, pp. 51-69). Según J.C. Bermejo, Mitología y Mitos de la Hispania Prerromana II, Madrid 1986, p. 36, estos testimonios corresponden a una situación en la que los hermanos dotaban a sus hermanas en compensación a sus esfuerzos por proporcionarles novias. Véase una revisión reciente de la cuestión del parentesco en los pueblos del Noroeste peninsular en R. Brañas, Indíxenas e Romanos na Galicia Céltica, Santiago 1995, 254-307 y passim. Sobre el matrimonio de Viriato, que también podría ser pertinente, véase García Quintela, Mitología y Mitos III, op. cit., pp. 193-211.

${ }^{56}$ BARBERo, Vigil, Formación, op. cit., pp. 237 y 300-1. 
FIGURA 1: Iconografía de los reyes de Pamplona. 1a : Fragmento de la miniatura del códice Vigiliano que representa a Sancho Garcés II de Pamplona. 1b y 1c : Fragmento de la miniatura del códice Emilianense que representa a Sancho Garcés II y a su hermano Ramiro de Viguera. 1d : Vista general de la miniatura del códice Vigiliano (la composición del códice Emilianense es idéntica).

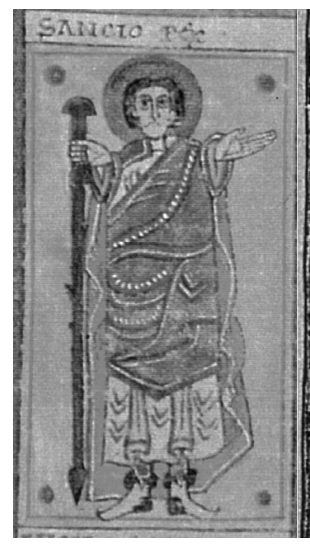

$1 \mathrm{a}$

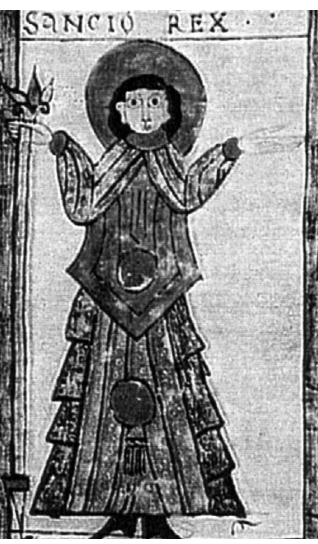

$1 b$

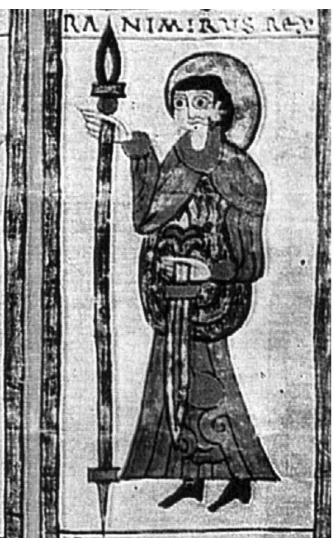

$1 \mathrm{c}$

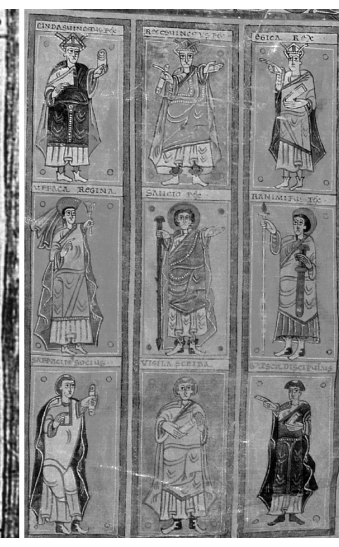

$1 d$

ta y en la antigüedad estuvieron rodeados por poblaciones célticas. Si tenemos en cuenta que la realeza en sus más diversos aspectos es un elemento clave de la cultura céltica y que los vascones, que se sepa, no tenían instituciones de ese estilo, pensar en que adoptaron esos elementos de sus vecinos cuando los necesitaron no parece fuera de lugar ${ }^{57}$. Además no adoptarían, adaptarían, exclusivamente el sistema sucesorio o de organización del linaje real. También se servían de emblemas y terminología de raíz céltica.

En primer lugar se puede considerar la diadema que portan los reyes de Navarra en las primeras miniaturas románicas que los representan, muy diferentes de las representaciones de coronas de otros reyes peninsulares (véase Figura 1a, 1b, 1c) ${ }^{58}$. Á. Martín Duque señala que el elemento en cuestión no es una corona, lo considera un

57 Véanse los apuntes de J. ArAnZAdi, Milenarismo vasco. Edad de oro, etnia y nativismo, Madrid, 2000 (1. a ed. 1981), pp. 270-1, 286-7, 345-6, 348; también F. DELPECH, «Le rituel du 'Pied déchaussé', Monosandalisme basque et inaugurations indo-européennes», Ollodagos 10, 1997, pp. 55-115.

${ }^{58}$ Miniaturas navarras del siglo X tomadas de S. DE Silva Y Verastegui, Iconografía del siglo X en el Reino de Pamplona-Nájera, Pamplona, 1984, láminas XXVI y XXVII entre pp. 416-417, comparadas con las representaciones de reyes reunidas por A. RUCQUOI, «De los reyes que no son taumaturgos: los fundamentos de la realeza en España», Relaciónes, 13, 51, 1992, pp. 55-100, láminas en pp. 85-100. Puede verse también la rica iconografía de la realeza recogida en el Tumbo A de la Catedral de Santiago, Santiago, 1998 (estudio y edición de M. LuCAS ÁlvAREz), de las 27 miniaturas 21 representan a reyes (incluida la reina Urraca) que menos Pedro I de Aragón (en p. 205, con la cabeza descubierta) están tocados con diferentes tipos de coronas, aunque los tocados de los primeros reyes 
FIGURA 2: El bronce res. Vista general de la cara B del "bronce res" donde se destaca la posición del pictograma solar y las letras que lo acompañan como encabezamiento.

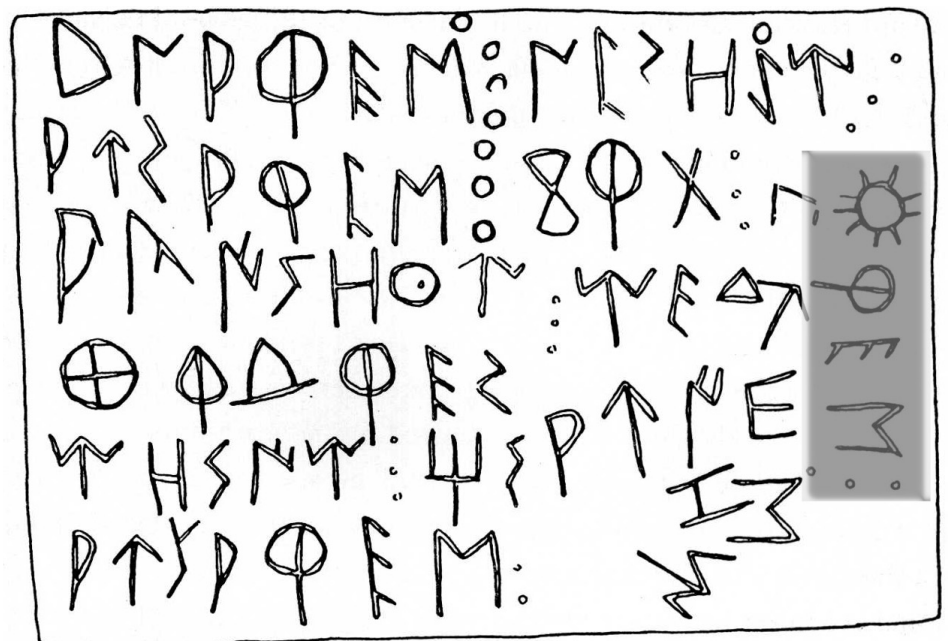

disco y apunta su simbología solar ${ }^{59}$. Un testimonio antiguo puede apoyar esta sugerencia: el llamado «bronce reś» escrito en lengua celtibérica con signario ibérico.

Allí se lee en dos ocasiones el término ausa-reś. La primera parte podría significar «esplendor» por su relación con la raíz indoeuropea *aues-, «iluminar», que reaparece en el latín aurōra $(<*$ ausōs-ā) mientras que reś se relaciona con el galo rīx y el latín rē $x^{60}$. Además en la cara $\mathrm{B}$ aparece, como en un encabezado, una representación del sol que precede a reś y podría ser el símbolo ideográfico del primer elemento ausa-reś, que en este contexto sería la autoridad suprema (véase Figura 2). En esta línea C. Jordán sugiere relacionar esa asociación entre pictograma y escritura alfabética con el nombre Solirix, atestiguado en la epigrafía galo-

de la dinastía asturiana podrían ser alguna clase de sombrero (véase pp. 49, 51, 53, 77, 104), aunque S. Moralejo los interpreta como «coronas muy sencillas, de un tipo sin duda arcaico para la época» en S. Moralejo Álvarez, «La miniatura en los Tumbos A y B», en M.C. Díaz y Díaz, F. López Alsina, S. Moralejo Álvarez, Los Tumbos de Compostela, Edilán, Madrid, 1985, pp. 44-62, la cita es de la p. 49 y cf. p. 51 sobre el tratamiento iconográfico excepcional de Pedro I de Aragón. En todo caso estos tocados difieren de la diadema de los navarros. La iconografía de los reyes leoneses representados en el Liber Testamenturum o Libro de las Estampas de la catedral de León, fechado en el siglo XII, responde al mismo modelo del Tumbo A de Santiago.

59 Á. MARTín DuQue, «Algunas observaciones sobre el carácter originario de la monarquía pamplonesa», Homenaje a José María Lacarra, Pamplona, 1986, tomo II, pp. 525-530 en p. 529 n. 22.

${ }^{60}$ W. MeID, Celtiberian Inscriptions, Budapest 1994, p. 45. 
latina ${ }^{61}$. Obviamente, de esta forma no se prueba la continuidad de un sistema iconográfico celtíbero a otro pamplonés alto medieval. Con todo, la analogía entre ambas formas de simbolizar la realeza en una misma zona parece clara.

En otros ritos e ideología de la realeza navarra se detectan otras posibles huellas de herencia céltica. Destaca la homología entre el nombre irlandés de la ceremonia de investidura real, banais rígi, que literalmente significa «matrimonio» $\mathrm{o}$ «fiesta de matrimonio de la realeza» ${ }^{62}$, y la exigencia que plantea el Fuero Antiguo de Navarra al hijo mayor del rey de «casar con el regno» ${ }^{63}$.

Por último, el rey Sancho Garcés II de Pamplona, en la miniatura antes indicada, lleva en su mano un cetro-cayado. La naturaleza del objeto se aprecia bien si lo comparamos con la lanza de su hermano Ramiro en la viñeta adyacente. En una de las representaciones (códice Vigiliano, Figura 1a) se aprecian las nudosidades de la vara en contraste con la lanza recta, en la otra (códice Emilianense Figura 1b) una floración en su extremo, en contraste con la punta de la lanza (Figura 1c) ${ }^{64}$. Este

${ }^{61}$ C. JORDÁn CólerA, Introducción al Celtibérico, Zaragoza 1998, p. 182; las inscripciones son CIL XII, 3005 y CIL XIII, 3095.

${ }^{62}$ P. MAC CANA, «An archaism in Irish poetic tradition», Celtica 8, 1968, pp. 174-191 en p. 181; JASKI, op. cit., pp. 63-6.

${ }^{63}$ Fuero General II, 4, 1, citado por J.M. LaCARRA Y De Miguel, El Juramento de los Reyes de Navarra: 1234-1329, Zaragoza, 1972, p. 15.

${ }^{64}$ Existe una asociación natural entre la idea de cetro y la de lanza, al menos para los griegos, Pausanias IX, 40, 11, dice en la ciudad beocia de Queronea se conserva el cetro que Hefesto hizo para Zeus y que llegó a manos de Agamenón, donde se le venera «llamándole lanza (dóry)»; y Justino 43, 3 , insiste al afirmar «hastas quas Graeci sceptra dicere». Obviamente la relación se establece a partir de la empuñadura de madera rectilínea del arma, el sentido primero del griego dóry es «madera» y el nombre del objeto en distintas lenguas insiste en ello, véase E. BENVENISTE, Vocabulario de las Instituciones indoeuropeas, Madrid, 1983, pp. 256-8. Basándome en esto considero que las diferencias de tratamiento iconográfico entre la lanza inequívoca de Ramiro y el cetro-cayado de Sancho, aunque pequeñas, son significativas. En este contexto podemos recordar, también la conclusión etimológica de Benveniste para el griego sképtron, «bastón de apoyo, de marcha» (p. 257), que se identifica, con toda naturalidad, con el cayado del pastor. Por otra parte, en la iconografía de la realeza en el Tumbo A de la Catedral de Santiago (supra n. 58) todos los reyes llevan cetro con la excepción, otra vez, de Pedro I de Aragón, algunos representados sobre un caballo cargando lo sustituyen, obviamente, por la lanza (pp. 232, 282, 316). En estos cetros la evocación vegetal aparece de dos formas, como floración en los primeros reyes asturianos (pp. 49, 53, 77, que reaparece en el cetro de Fernando III, p. 307) o con una evocación vegetal menos precisa (pp. 109, 130, 142, 155, 177) que se alterna con cetros decorados con cabeza de felino (pp. 104, 116, 125, 160, 164) mientras que el cetro de Alfonso VII parece combinar el motivo vegetal con el felino (p. 209). Al igual que con respecto a la corona, también la iconografía del leonés Liber Testamentorum sigue ese modelo respecto al cetro. En cualquier caso estos cetros, de medio cuerpo de altura y asidos con la mano izquierda por su extremo inferior, se diferencian bien del bastón o cayado de marcha que lleva Sancho de Pamplona, alto como el rey que lo porta en su diestra. Los análisis sobre estas cuestiones de P.E. Schramm, Las Insignias de la Realeza en la Edad Media Española, Madrid, 1960, son más arqueológicos o de historia del arte que simbólicos. Con respecto a los temas evocados indica que la corona de los reyes astures es de procedencia 
elemento simbólico concuerda con el vestido campesino que debe llevar el señor de Vizcaya cuando jura su cargo en Guernica y con el cayado que lleva el archiduque de Carintia también en su rito de investidura, derivando ambos ritos, probablemente, de un fondo céltico ${ }^{65}$.

Si contemplamos ahora la distribución espacial de estos hechos en el mapa peninsular observamos que nuestros testimonios se ubican, grosso modo, un poco más allá de las fronteras de la Celtiberia antigua. Pero cuando tenemos documentación para esta zona la realeza ha desaparecido, en un proceso tal vez comparable con el de sus parientes galos. Las fuentes disponibles remiten al período inmediatamente anterior, cuando Celtiberia era periférica en el teatro de operaciones por lo que no contamos con documentación directa sobre esa zona. En este sentido Celtiberia, o lo céltico, sería algo así como el mínimo común denominador genético que explicase las semejanzas detectadas en los cuatro casos examinados, al margen de que es posible en el caso astur una herencia céltica directa, diferenciada de la celtíbera. Además, los testimonios marginales, de peor calidad, que aducíamos indican expresamente la etnia celta de las parejas de jefes citadas.

Con respecto a los testimonios medievales existe un problema temporal, ¿cómo pudo conservarse durante siglos una tradición de jefaturas locales autóctonas cuando Roma había transformado profundamente la situación política y social de la Península Ibérica? Hace años P. Bosch Gimpera proponía una respuesta cuando destacaba las continuidades entre la Hispania prerromana y la alto medieval ${ }^{66}$. Más tarde J. Caro Baroja concluía sus Pueblos de España con afirmaciones del mismo tenor ${ }^{67}$. La hipótesis que acabamos de presentar, limitada a una institución de indudable relieve, se ubica, caso de aceptarse los hechos y argumentos presentados, en el marco de estas continuidades.

carolingia buscada por Alfonso III como modo de diferenciarse de los gobernantes navarros que a principios del siglo X comenzaron a autodenominarse reyes (pp. 22-24). Sobre el cetro dice «en las fuentes escritas, la mención del cetro es extraordinariamente rara. En comparación con el resto del Occidente, parece que el cetro tuvo, desde un principio, un papel mucho menos importante que en otros países cristianos» (pp. 81-82). Sin embargo, los elementos iconográficos aquí reunidos apuntan, al menos, a la existencia de esa importancia simbólica, heredada o latente, como muestra el contraste entre los cetros y coronas navarros y astures en representaciones iconográficas coetáneas. El tratamiento de MORALEJo, art. cit, p. 49, sobre los cetros es insuficiente.

65 Datos en DelPECh, «Le rituel», art. cit., parcialmente recogidos en García Quintela, SANTOS ESTÉvEZ, «Petroglifos podomorfos», art. cit., pp. 17-20.

${ }^{66}$ P. Bosch Gimpera, España, Anales de la Universidad de Valencia, Segunda Epoca, Valencia, 1937; ID., El Poblamiento Antiguo y la Formación de los Pueblos de España, México, 1944, p. 25, por ejemplo.

67 J. Caro Baroja, Los Pueblos de España, Madrid 1981 (1era ed. 1946), pp. 17-18, 426. Llega a la misma conclusión para Asturias, desde el punto de vista de la Historia del Arte, H. SchlunK, Ars Hispaniae, vol. II, Madrid, 1947, pp. 346 ss. 


\subsection{Aspectos de tradición germánica}

Lo dicho hasta ahora a favor de una hipotética génesis céltica puede ser todo lo razonable que se quiera, pero no agota el problema.

Entre poblaciones germánicas de época medieval semejante a los testimonios hispanos considerados también aparecen casos de sucesión o cooperación entre hermanos a la hora de gobernar. Unas veces de forma intrascendente ${ }^{68}$, otras reflejando la historización de tradiciones legendarias sobre la pareja dioscúrica del panteón germánico ${ }^{69}$. Además algunos rasgos de la realeza navarra parecen de tradición germánica. Así, el cetro-cayado que caracteriza a Sancho Garcés II también distingue al rey visigodo Wamba o Bamba $^{70}$. Tampoco es ajena a la tradición germánica la idea de una mujer que simboliza el reino, o es depositaria de la realeza, y escoge a un marido al que, de esta forma, confiere la realeza ${ }^{71}$.

${ }^{68}$ No pretendo un conocimiento de hechos germánicos lejos de mi competencia, me detengo en ellos debido en buena medida al sugerente trabajo de K. Kristiansen. En cualquier caso la lectura de Adam de Bremen, Historia de los arzobispos de Hamburgo, presenta diversos casos de cooperación o lucha de hermanos en la esfera de la realeza: II, 3 y 6 sobre el rey Otón y sus hermanos; II, 26, escolio 21, Venceslao príncipe de Bohemia es martirizado por su hermano Boleslav, que se apodera de su reino (se trata de eslavos); II, 73-74, reparto de reinos entre hermanos y luchas fraticidas; III, 13, Harald hermano de Olav el santo de Noruega se exilia en primera instancia pero es reclamado para heredar a su hermano fallecido, pero encuentra el trono ocupado por su pariente Sven con quien guerrea sin tregua; III, 43-5, hermanos (con título de condes) de común acuerdo contra un arzobispo que los divide. En IV 22, dice de los suecos que «tienen reyes, según una antigua tradición, pero su poder depende de la voluntad del pueblo», este detalle tiene un paralelo preciso en César $B G$ V 27, 3, cuando Ambiorix afirma que «su autoridad era de tal índole que la multitud mandaba sobre él tanto como él sobre la multitud». Idea que ya existe entre los germanos antiguos, pues Tácito Germania 11, 2, indica que los jefes en la asamblea adoptan decisiones siendo «la influencia de la persuasión más importante que el poder de ordenar» y señala la capacidad de los guerreros asistentes para aprobar o rehusar la iniciativa propuesta.

${ }^{69}$ Véase WAGNER, art. cit., pp. 228-235; WARD, Divine Twins, op. cit., pp. 50-6, con casos de parejas de reyes hermanos que desempeñan un papel fundacional o inaugural de procesos políticos y sociales. Wagner destaca la aparición de parejas de jefes dirigiendo grupos de guerreros jóvenes que fundan ciudades o estados; Ward, siguiendo a J. de Vries, sugiere que la mitología germánica de los gemelos divinos cristalizaría dando lugar a monarquías duales de carácter histórico (pp. 57-60).

${ }^{70}$ Las leyendas relacionadas con su acceso al trono cuentan que rechazó la corona que se le ofrecía hasta que floreciese su bastón plantado en el suelo, cosa que ocurrió obligándole a cambiar sus intenciones, véase A.H. KRAPPE, «The Ploughman King. A comparative study in literature and folklore», Revue hispanique 46, 1919, pp. 516-46, pp. 535-6 con bibliografía en n. 48; e ID. «The Ploughman King II», Revue hispanique 56, 1922, pp. 265-84, p. 277, en ambos estudios este autor indica que, aunque el tema tiene una larga vida hebrea y cristiana, la semejanza entre la historia de Wamba y el rey Premysl de Bohemia refleja un estadio precristiano (véase además del mismo autor en torno al motivo del rey labrador «La légende de Libuse et de Premysl», Revue des Études Slaves 3, 1923, pp. 86-9; «A Flemish legend of the Ploughman King», Leuvens e Bijdragen 16, 1924, pp. 93-100); insiste en esta idea F. DELPECH, «Rite, légende, mythe et société: fondations et fondateurs dans la tradition folklorique de la péninsule Ibérique», Medieval Folklore 1, 1991, pp. 10-56, en especial pp. 30-2.

${ }^{71}$ Además de los casos legendarios o míticos tratados por G. DumÉzIL, Del mito a la novela. La 
Si consideramos, entonces, que la realeza visigótica está mucho más cerca temporalmente de las dinastías hispanas medievales que hemos examinado, y que estas dinastías buscan explícitamente una legitimidad goticista» $^{72}$, es posible buscar el origen de los rasgos señalados en la tradición germánica, aunque entre los visigodos hispanos no haya sucesión entre hermanos. Pero esta explicación, si la tuviésemos que aceptar, no daría cuenta de los fenómenos de la antigüedad. Nos quedan, pues, dos alternativas.

La primera consideraría un origen doble de un mismo rasgo. Las similitudes entre los fenómenos antiguos y medievales serían, entonces, el resultado híbrido del influjo de dos sistemas sucesorios similares en sus formas pero genéticamente diferentes, uno céltico en la antigüedad, otro germánico en el medioevo.

saga de Hadingus (Saxo Gramático, I, v-viii) y otros ensayos, México, 1973 (París, 1970), pp. 34-5, 40-6: (Hadingus es rey antes de que Regnilda lo escoja; Niordr es un dios de tercera función, por tanto no es rey, escogido por Skadi), hemos de contar con casos lombardos y sajones explicados en M. J EnRIGHT, Lady with a Mead Cup. Ritual, Prophecy and Lordship in the European Warband from La Tène to the Viking Age, Dublín, 1996, pp. 25-6, por lo que sería un modelo propio de todos los germanos. Cabe recordar las páginas que J.G. FRAZER, Le Rameau d'Or. I. Le roi magicien dans la société primitive, París 1981, pp. 413-22, dedicó al acceso a la realeza por vía femenina. Es pertinente el ejemplo lidio, donde la mujer del rey legítimo Candaules, contemplada desnuda por Giges, le plantea a este la alternativa «o bien matas a Candaules y te haces conmigo y con el reino de los lidios, o bien eres tú quien debe morir sin más demora» (Heródoto I 11,2). El segundo testimonio queda más cerca de nuestro tema: Herminthruda, reina de los pictos, «era reina e incluso rey en la medida que su sexo se lo permitía; lo cierto es que ella haría rey al que considerase digno de su lecho. El elegido obtendría el reino con su mano» (Saxo Grammaticus, La Geste des Danois IV, 16, trad. J.-P. Troadec). Un poco antes Herminthruda se presenta con cualidades que recuerdan las que la irlandesa Mebd se atribuye a sí misma y exige de su esposo en la épica irlandesa la Razzia de las vacas de Cooley, aunque sin una presentación tan clara. Existen dudas sobre la familia étnica de los pictos, pero al menos en la época alto medieval reflejada por Saxo Gramático el territorio escocés estaba celtizado desde Irlanda, independientemente de que este proceso se efectuase sobre un fondo cultural anterior también celta. A estos casos se podrían añadir dos situaciones de la Odisea: el acceso a la realeza de Ítaca a través de la boda con Penélope que intentan los pretendientes y la naturalidad con la que Nausicaa contempla a Odiseo, náufrago extranjero, como eventual pretendiente y heredero al trono. Por otro lado, la leyenda bohemia de Libuse y Premysl parte de una inquietud análoga: los súbditos de Libuse, cansados de estar gobernados por una mujer, le pidieron que tomase esposo para que reinase un varón. Krappe en los artículos citados en la n. 69 estudia la historia, aunque se detiene poco en este detalle (artículo de 1922, pp. 270-2). En cuanto a ésta última leyenda, ¿hemos de recordar el sustrato céltico de Bohemia?

72 Es lo que sostiene Sánchez Albornoz para los astures, como hemos visto. Un detalle relevante para los Jimeno de Pamplona es la iconografía de las miniaturas de códices que contenían copias de legislación visigoda (Figura 1d). Ambas miniaturas tienen idéntica estructura. El registro superior representa a reyes visigodos legisladores (Chindasvinto, Recesvinto y Egica). El registro central a los reyes con Sancho Garcés II en posición central, su esposa Urraca a su derecha y Ramiro de Viguera a su izquierda. El registro inferior lo ocupan en el Códice Vigiliano los escribas y miniaturistas del códice: Vigila, Sarracino y García, que cambian en la miniatura del Códice Emilianense. Se expresa, de este modo, la perpetuación en el tiempo de un corpus jurídico que hunde sus raíces en la tradición visigoda. 
La segunda alternativa parte de la antigüedad de los testimonios reunidos por K. Kristiansen. Soy consciente de que se podría plantear la raíz indoeuropea de tales usos de diversas maneras. Por un lado adoptando la tesis difusionista del propio autor, ya que habría que mirar hacia la Grecia micénica (pero ¿qué hacer, entonces, con los testimonios minoicos, no indoeuropeos y los aspectos no indoeuropeos del wanax micénico destacados por T.G. Palaima (supra n. 28)? Por otro lado recurriendo a los caminos de la expansión indoeuropea en el tercer y segundo milenios por el continente europeo. Pero esta clase de alternativas me parece que suponen interpretar la noche mediante las tinieblas. No porque considere que tales situaciones no hayan podido darse en la prehistoria ${ }^{73}$, sino porque la incertidumbre del análisis no se despejaría, seguiríamos en el terreno de las hipótesis mejor o peor fundadas.

\section{UNA EXPLICACIÓN TIPOLÓGICA}

Por ello que creo que no debe descartarse otra posibilidad que no sería contradictoria con las anteriores. La cuestión podría plantearse como sigue: al margen de, o en paralelo con, las tradiciones acerca de los modos de institucionalización de las distintas realezas que hemos evocado existiría una necesidad funcional . Si algo tienen en común los distintos reyes evocados es que son jefes de guerra, líderes naturales de ejércitos que parten incesantemente en campaña. En estas condiciones la muerte del rey en la guerra sería una situación que se produciría con cierta frecuencia, sobre todo si se exige al jefe militar, como ocurre en tantas culturas, dar pruebas personales de valor. Pero un rey muerto en estas circunstancias plantea dos problemas: la inmediata continuación de la lucha o la campaña y la cuestión sucesoria.

\footnotetext{
${ }^{73}$ Véase B. Sergent, Les Indo-Européens. Histoire, langues, mythes, París 1995, p. 411, que dice refiriéndose a Suecia y el Norte de Europa central: «nace así una 'cultura nórdica', muy brillante a continuación en la edad del bronce, y prosigue sin cesuras hasta que sus portadores se revelan, al final del primer milenio a. de C., como germanos», y pp. 394-434, para un análisis de la expansión indoeuropea. WARD, Divine Twins, op. cit., passim, construye su libro como una búsqueda diferenciada de la presencia de los gemelos divinos de raíz indoeuropea en el mundo germánico y en la diferencia entre los rasgos globalmente indoeuropeos y otros casos de gemelos divinos en otras áreas culturales. Otra propuesta es la de T.V. GAMKRELIDZE, V.V. IVANOv, Indo-European and the Indo-Europeans: a reconstruction and historical analysis of a proto-language and a proto-culture, Berlín 1995, pp. 8445. Desde el punto de vista de una antropología indoeuropea el difundido ensayo de C. RENFrEw, Archaeology and language. The Puzzle of Indo-European Origins, Nueva York, 1988, no resulta aceptable; véanse los argumentos adelantados en la recensión a la edición francesa del libro (París 1990) por B. SERGENT, Annales E.S.C. 47/2, pp. 389-94.
} 
En cuanto al primero, si se pretende que la muerte del rey en campaña no se convierta en una derrota segura es necesaria la existencia de una alternativa de repuesto en el mando, inmediata y aceptada por el ejército movilizado de manera indiscutible. Creo que los testimonios sobre dos jefes de guerra, hermanos o no, que hemos recogido, en donde de una u otra forma se resalta la primacía de uno de ellos se entienden en esta clase de situaciones ${ }^{74}$. Además esta explicación se ve corroborada indirectamente por un testimonio irlandés, aunque es tardío. Procede de Edmund Spenser quien, según K. Simms que lo cita, proporciona una buena descripción de las funciones del tánaiste en el siglo XVI, una de ellas consistía en evitar el gobierno de un menor pues:

«El tanist está siempre disponible, si sucediese que el Captain [título en el que deriva tardíamente el de los antiguos reyes irlandeses] muriese de repente o fuese muerto en la batalla, estuviese lejos del país, para defenderlo y protegerlo de toda esta clase de dudas y peligros: por estas causas también se cede al tanist una parte del país, y ciertas porciones y gastos correspondientes a todos los habitantes, súbditos del señor».

Añade K. Simms que cada detalle parece corroborado en Irlanda por referencias más antiguas ${ }^{75}$. Y, podríamos añadir, por muchos de los testimonios de asociación real que hemos reunido.

En este contexto la sucesión a la realeza no tendría que ver con la cuestión del liderazgo militar vacante. Es decir, el problema anterior se podría resolver, al menos teóricamente, con el recurso a un segundo expresamente designado para tal eventualidad, dejando en suspenso la cuestión sucesoria hasta un momento más apropiado. Pero buena parte de nuestros testimonios no apuntan en esta dirección. Reconozcamos enseguida que la opción de una sucesión en la realeza por medio de una herencia directa no es realista. En muchas ocasiones un rey muerto en campaña podría ser lo bastante joven como para que su hijo fuese todavía un niño. Es aquí donde el recurso a los hermanos, o parientes cercanos de la misma generación, se impone con claridad. Por una parte, porque pueden resolver satisfactoriamente la continuidad de la campaña militar en la que hubiese caído el rey que la inició, por otra, porque garantizan la permanencia del privilegio real en el mismo linaje, finalmente, porque los mecanismos de «asociación real» pueden suponer, de hecho, una participación en los beneficios simbólicos inherentes a la investidura real. Que esta «asociación» se haga mediante un matrimonio especial, mediante una participación

\footnotetext{
74 Véase un caso infra n. 76.

75 SimMs, op. cit., p. 56.
} 
subordinada de la legitimidad conferida por el rito de investidura, o mediante el derecho a llevar el título real en áreas determinadas, es lo de menos, lo que importa es que de una u otra forma el hermano o pariente cercano «asociado» a la realeza tiene la legitimidad necesaria como para heredar a su antecesor de forma inmediata.

Esto es cierto desde el punto de vista «tipológico»o «funcional», si se prefiere, que adopto ahora. Pero desde el punto de vista «genético» los modos concretos, los procedimientos por medio de los cuales se resuelve el problema de la asociación, son determinantes para establecer la familia cultural en la que se ubica la institución cuyo funcionamiento detectamos en nuestros testimonios. Dicho de otra forma, la tipología de las situaciones detectadas pone de relieve la existencia de un problema que cada tradición cultural resuelve a su manera.

Por tanto considero que la explicación genética y la tipológica no son contradictorias sino más bien complementarias. Cada una de ellas soluciona y deja pendientes problemas específicos. La explicación genética permite entrar en ciertos detalles de nuestros testimonios, concernientes sobre todo a procedimientos rituales o institucionales, que la explicación tipológica no puede resolver. Por el contrario, la explicación tipológica puede obviar las aporías de la explicación genética cuando no es capaz de resolver determinadas cuestiones debido a la carencia de documentación suficiente o a la impericia del análisis.

En cualquier caso la realeza espartana va por otro lado. Los dos reyes pertenecen a dinastías diferentes que suprimen de un plumazo todos los problemas fraternales y de parentesco que nos han ocupado aquí. Además los dos reyes raramente partían juntos en campaña, y esta eventualidad se prohibió expresamente a fines del siglo VI a. de C. ${ }^{76}$ Incluso en las tradiciones relativas a los reyes se llegó a plasmar paulatinamente una forma de sistematización, posiblemente de herencia indoeuropea, que presenta una de las dinastías como especialmente pacífica (mitraica) y a la otra como fundamentalmente guerrera (varuniana) ${ }^{77}$.

Tampoco esto tiene que ver con el carácter guerrero de las parejas de jefes que hemos tratado. Además, la realeza espartana es un único en Grecia Antigua, mientras que, si consideramos la diferencia abismal entre la abundancia de fuentes dis-

\footnotetext{
${ }^{76}$ Cleómenes y Demarato no pudieron someter a Atenas por su desacuerdo el año 510 a. de C., desce entonces los espartanos decidieron que solo saliese en campaña uno de los reyes, Heródoto (V, 75, 2). Véase el comentario de CARLIER, op. cit., pp. 259-60.

77 Véase B. SERGENT, «La représentation spartiate de la royauté», Revue de l'histoire des religions 189/1, 1976, pp. 3-52. Otra forma de actualizar la tradición indoeuropea en parejas de reyes es la constituida temporalmente por Rómulo, que porta los valores de la primera y segunda funciones, y Tito Tacio, que porta los de la tercera. Véase supra n. 31. Sobre la realeza espartana es básico el tratamiento de CARLIER, op. cit., 240-324.
} 
ponibles para Grecia e Iberia antiguas, parece ser un rasgo relativamente difundido entre algunos pueblos de la Hispania Antigua y Medieval. Por último, si en Grecia hemos de buscar un paralelo a las situaciones peninsulares descritas, será en dirección a los basileeis de Tesalia u otras fórmulas de pluralidad de reyes que pudiera haber en ese contexto ${ }^{78}$.

\section{Apéndice 1}

\section{DIOSCURISMO INDOEUROPEO Y PAREJAS DE REYES HISPANOS}

Puede ser útil evocar al margen del argumento presentado, un tema tal vez relacionado. Se trata del motivo mitológico o legendario del dioscurismo de tradición indoeuropea que podría servir de referente o sanción ideológica a prácticas institucionales de las realezas hispanas como las examinadas. El estudio de referencia es un artículo de S. Wikander ${ }^{79}$ donde se analizan las diferencias entre los integrantes de la pareja divina por antonomasia del panteón védico, los Ashvin prolongados en la epopeya por sus hijos, los gemelos Nakula y Sahadeva, mostrando la vocación bélica y afinidades con los caballos el primero en contraste con las tendencias pacifistas, afición por sabiduría y apariencia de boyero que adopta el segundo, dualidad que en otros gemelos indoeuropeos prolongan con diversos rasgos específicos, tal como explicó G. Dumézil prolongando los análisis de Wikander ${ }^{80}$.

Paralelamente apareció el estudio de D. J. Ward centrado en parejas de gemelos en el mundo germánico ${ }^{81}$ que amplió en un artículo sobre la dualidad funcional de los integrantes del $\mathrm{par}^{82}$, donde hizo una aportación de interés para nuestro argumento.

\footnotetext{
${ }^{78}$ Considerando, por ejemplo, parejas de tipo dioscúrico como las catalogadas por WAGNER, art. cit., pp. 4-8 y 235-8, o situaciones como los basileeis de Feacia en la Odisea.

${ }^{79}$ S. WIKANDER, «Nakula et Sahadeva», Orientalia Suecana 6, 1957, pp. 66-96.

${ }^{80} \mathrm{G}$. DumÉZIL, Mythe et épopée I, L'idéologie des tríos fonctions dans les épopées des peuples indo-européens, París, 1986 (1. a ed. 1968), pp. 71-86. En cuanto a la función diferenciada de los gemelos dioscúricos también es importante la serie de estudios incluida en un libro póstumo de G. DuMÉziL, Le roman des jumeaux et autres essais, París, 1994, pp. 19-165, aunque no todos los temas tratan estrictamente de hermanos gemelos. Previamente había abordado la cuestión en el último capítulo de ID, Del mito a la novela, op. cit., pp. 118-33. En el mismo libro reproduce un ensayo publicado inicialmente como primer apéndice de La Saga de Hadingus (1953), «el ahogado y el colgado», donde dedica a algunas páginas a parejas dioscúricas (pp. 158-60). Estas mismas páginas están reeditadas en G. DumÉzIL, Mythes et dieux de la Scandinavie ancienne, París, 2000 (ed. de F.-X. Dillmann), pp. $112-15$.

${ }^{81}$ WARD, Divine Twins, op. cit.

${ }^{82}$ D. J. WARD, «Separate Functions of the Indo-European Divine Twins», en J. Puhvel ed., Myth
} 
Se trata de la frecuencia con que los germanos que se expanden por el territorio del Imperio Romano aparecen encabezados por parejas de dirigentes. Hengist y Horsa son hermanos y dirigentes de la invasión sajona de Gran Bretaña, sus nombres significan «semental» y «caballo», dimensión teriomorfa propia de los gemelos divinos de tradición indoeuropea, y además aparece una diferenciación entre ambos que lleva a la gradual desaparición de Horsa, motivo también frecuente en las parejas dioscúricas. Al mismo tiempo Ward recuerda que los dirigentes de los vándalos fueron Ambr y Assi, los de los longobardos Ibor y Aio, o Aggo y Ebbo en otras versiones, los de los asdingos Raus y Raptus e indica que todo parece indicar que estas parejas proceden de la evemerización o institucionalización de una tradición mitológica y religiosa en donde divinidades de tipo dioscúrico eran especialmente importantes ${ }^{83}$.

El propio D. Ward devuelve la cuestión a la Península Ibérica al destacar una tradición marginal sobre la concepción de El Cid que lo presenta como un gemelo. En efecto, la madre del héroe castellano era la esposa de un molinero. En cierta ocasión violó a esta mujer el caballero Don Diego Laínez concibiendo de esta unión al que iba ser El Cid. Pero ese mismo día la mujer tuvo relaciones con su esposo concibiendo a otro hijo. Ambos nacieron como gemelos pero crecieron diferentes por su aspecto y carácter. En particular el primero tenía una afición notable por confeccionar juguetes que representaban caballos y armas mientras que el segundo hacía juguetes en forma de bueyes y $\operatorname{arados}^{84}$.

La semejanza de lo relatado en este episodio con las cualidades diferenciadas de otros gemelos de tradición indoeuropea y germánica en particular son nítidas, aunque Ward no explica cómo pueden aparecer en una tradición hispana marginal.

El tema no queda aquí, pues existen en la España medieval reflejos de tradiciones dioscúricas: en forma santos dobles, de cuestiones de gemelidad, de realeza doble, o de complejidad de las relaciones fraternales en el ámbito de la realeza, estudiados por A. H. Krappe y F. Delpech, considerando motivos hagiográficos, literarios y/o folclóricos, sin descuidar diversas tradiciones históricas ${ }^{85}$.

and Law among the Indo-Europeans. Studies in Indo-European Comparative Mythology, Berkeley y Los Ángeles, Londres 1970, pp. 193-202, el tema ya tenía desarrollos importantes en The Divine Twins, pp. 20-24, 37-8, 48, 55-6.

83 Ibídem, pp. 50-56 y bibliografía de la p. 124, ID, «Separate Functions», pp. 199-200, donde sigue expresamente a WAGNER, art. cit., pp. 228-35.

${ }^{84}$ WARD, «Separate Funcions», art. cit., pp. 201-2, citando el «Compendio historial», 2. ${ }^{\text {a }}$ redacción, Biblioteca Nacional de Madrid, MS 1525, F. 115, folio 248r, conocido como MS F., ya había tocado el tema en The Divine Twins, pp. 23-4 y 56.

85 A.H. KRaPPE, «Spanish Twin Cults», Studi e Materiali di Storia dei Religioni, 8, 1932, pp. 122 , pero no todos sus ejemplos son convincentes y se limita a yuxtaponerlos sin un verdadero análi- 
Sin embargo, nada de esto parece tener una relación directa con las situaciones históricas que hemos examinado. Ello es obvio en los magros textos relativos a los casos antiguos, carentes en su sequedad de toda posibilidad de enganche de motivos ideológicos del tipo que sea. Pero otro tanto ocurre, lamentablemente, en los casos altomedievales, donde la orientación de las crónicas reales de las dinastías examinadas tampoco permite el paso de un plano histórico-cronístico a otro legendario. No olvidemos, por lo demás, que la legitimidad expresamente buscada por esos reyes es la derivada de la religión cristiana y de la realeza visigoda, por lo demás pionera en la asunción de elementos de legitimación cristiana de la función real.

Es decir, si hay una herencia de motivos arcaicos, germanos o celtas, en los usos institucionales examinados y en las tradiciones dioscúricas hispanas, esos motivos se han mantenido por separado sin otra posibilidad para el analista que evocar su hipotética unidad estructural en un pasado impreciso pero probablemente remoto. Dicho de otra forma: desconozco cómo y cuándo pudieron relacionarse los mencionados usos y tradiciones.

\section{Apéndice 2}

\section{PAREJAS DE REYES CÉLTICOS}

La conclusión anterior también es válida si consideramos el mundo céltico de modo global, pues se han catalogado los rasgos dioscúricos presentes en la mitología y el folclore celtas ${ }^{86}$. Sin embargo no se ha visto cómo esos rasgos se pueden continuar en parejas de reyes más o menos legendarios o históricos que conocemos (recordemos que en los testimonios germánicos la etimología de los nombres de

\footnotetext{
sis. F. DELPECH, «Un souverain, un ange et quelques folies: avatars d'un 'exemplum' médieval», en A. REDOndo y A. Rochon (eds.), Visages de la folie (1500-1650), París, 1981, pp. 55-65, explora el tema de la dualidad del rey; ID., «Les jumeaux exclus: cheminements hispaniques d'une mythologie de l'impureté», en A. REDONDO (ed.) Les problèmes de l'exclusion en Espagne (XVIe-XVIIIe siècles), París, 1983, pp. 177-203, rastrea en los gemelos hispanos motivos de herencia indoeuropea; ID., «Fragments hispaniques...», art. cit., pp. 107-18, sobre incesto y realeza y pp. 118-27 sobre sus prolongaciones en el folclore.

${ }^{86}$ A.MinARD, «Of Horses and Humans: The Divine Twins in Celtic Mythology and Folklore», en K. Jones-Bley et al., Proceedings of the Ninth Annual UCLA Indo-European Conference, Journal of Indo-European Studies Monograph Series, No. 28, Washington, 1998, pp. 158-178, aunque no recoge el dato, en mi opinión relevante, de que el propio Lug, en su forma galesa como Lleu, es un gemelo que nace al mismo tiempo que Dylan, si bien sus destinos son diferentes. Sobre el misterioso hermano de Lleu y el carácter dioscúrico de la pareja véase G. DumÉzIL, L'oubli de l'homme et l'honneur des dieux, Esquisses de mythologie, París, 1985, pp. 105-9 e IDEM., Mythes et dieux de la Scandinavie, op. cit., p. 188 n. 1.
} 
algunos reyes fundadores remiten a un ámbito hípico, específico del dioscurismo).

Otro problema es que, desde un punto de vista metodológico me parece equívoco construir argumentaciones a propósito de la sociedad o instituciones célticas partiendo a priori de su semejanza básica ${ }^{87}$. Se hace, más o menos conscientemente, como si tiempos y lugares muy diferentes participasen de un continuo cultural inalterado e inalterable. No se trata de negar la existencia de una «cultura céltica» que se extendió en algún momento desde Ancyra hasta Tara, de la misma forma que existió una «cultura griega» desde Ampurias hasta Aï Khanum. Lo que ocurre es que mientras que los componentes de esta última se han constituido desde hace siglos y forman parte de un estándar académico bien establecido, esto no ocurre así con respecto a los estudios célticos, que muchas veces carecen de un mínimo lenguaje de entendimiento entre los cultivadores de sus diferentes ramas. Por ello me parece fuente de errores construir argumentos acumulando noticias puntuales espigadas de fuentes relativas a áreas y momentos muy diferentes.

En el corpus del trabajo precedente, por el contrario, se han comparado dos situaciones diferentes y relativamente bien documentadas, la realeza irlandesa alto medieval descrita en una bibliografía solvente, y una serie de testimonios hispáni-

${ }^{87}$ Soy consciente que se hace con relativa frecuencia y predicamento en el ámbito de los estudios mitológicos recientes (pienso en los trabajos de Claude Sterckx y de algunos de los colaboradores habituales de la revista Ollodagos), en este caso la práctica cuenta con el precedente de una tradición comparativa (fundada a su modo por H. D'Arbois de Jubainville a fines del siglo XIX y asentada con fuerza especial por muchos trabajos de Ch.-J. Guyonvarc'h y F. Le Roux desde los años 50 del siglo $\mathrm{XX}$ ) que sostiene la oportunidad de la consideración común de datos de la esfera religiosa conocidos en el continente en la antigüedad con datos mitológicos tomados del «conservatorio» de tradición céltica que fue la Irlanda medieval (sin olvidar el País de Gales).

Pero lo que puede ser cierto en el ámbito de la religión y el mito, no tiene por qué serlo en los planos social e institucional, y si así es, debe explicarse con detalle (este problema está presente en un clásico como H. HUBERT, Los celtas y la civilización céltica, Madrid 1988, edición original de 1932, en sus capítulos sobre la sociedad céltica, pp. 417-94, donde yuxtapone informaciones insulares medievales y continentales antiguas indicando sus analogías, ciertas, pero sin comentar la naturaleza muy diferente de los testimonios escogidos, por ejemplo textos mitológicos irlandeses comparados con etnografía clásica). Ello se debe a la compleja serie de influjos contrapuestos a los que se ven sometidos los celtas en su proceso histórico de expansión europea y microasiática, considerando, sobre todo, que cuando los conocemos mejor ya están firmemente asentados en sus territorios de destino y sometidos a influjos diversos.

Pongamos dos ejemplos extremos. Por una parte los gálatas de Anatolia se helenizan, tal como refleja su sistema institucional descrito por Estrabón, mientras que los celtas de la Península Ibérica adoptan de sus vecinos iberos (a su vez bajo influjo púnico) usos como la escritura, la moneda y la forma de vida en ciudades de tipo mediterráneo. Se aborda parcialmente este problema y propone una forma de solventarlo en GARCíA QuiNTELA, «Le programme d'accès à la royauté dans le monde celtique», art.cit. Véase también la puesta a punto de P. Sims-Williams, «Celtomania and Celtoscepticism», Cambrian Medieval Celtic Studies, 36, 1998, pp. 1-35 con abundante bibliografía. 
cos bien establecidos. Sin embargo, aún así, se producían las dudas indicadas para explicar satisfactoriamente las situaciones peninsulares.

Por ello he optado por reservar para este apéndice testimonios de parejas de reyes procedentes de otros horizontes del mundo céltico. En principio su presencia aboga a favor de una explicación genética cuya raíz, a su vez, puede ser doble a la luz de los elementos que conocemos. Por una parte estas parejas podrían ser el reflejo de una institución pancéltica de asociación real. Por otra, constituirían la forma de cristalizar en el registro institucional tradiciones míticas de tipo dioscúrico, sin que, como decíamos al principio de este apéndice y al final del anterior, sepamos hasta qué punto ambas explicaciones pudieron fundirse en algún momento desconocido del pasado.

Sin embargo, la carencia de detalles significativos en nuestra documentación a favor de cualquiera de dos explicaciones propuestas o de su eventual fusión, invita a dejar la cuestión en suspenso. Por lo tanto, admitiremos una práctica de la realeza (o gobierno) por medio de parejas (cuyo grado de difusión, además, habría que aquilatar) como una posibilidad pendiente de demostración. Entre tanto nos conformaremos pensando que estamos ante situaciones comparables tipológicamente, como las evocadas más arriba: estamos, en muchos casos, ante contextos bélicos donde se plantea la eventualidad de la muerte del rey en campaña.

1. Beloveso y Segoveso son los sobrinos del legendario rey galo Ambigato a los que éste, en su vejez, ante el exceso de población en la Galia encomienda dirigir migraciones de galos hacia Italia y la selva Herciniana, respectivamente. En realidad no son, pues, jefes conjuntos, aunque desempeñan una función análoga y son hermanos ${ }^{88}$.

2. Momoro y Atepomaro tienen cierta semejanza con los anteriores. Son los legendarios fundadores de Lugduno (Lyon) que habían sido expulsados de su hogar por Sereroneo. De Momoro se nos dice que era augur y el nombre de Atepomaro se puede interpretar como «caballo muy grande», epíteto del dios Lug que en la versión galesa de su mito, el Mabinogi de Math, es un gemelo ${ }^{89}$.

3. Lonnorio y Lutario son los reges de los celtas que invaden Asia Menor (277 a. de C.) tras escindirse del grupo de Brenno ${ }^{90}$. Es interesante para nuestro

88 Tito Livio V 34-35, 1.

${ }^{89}$ Pseudo-Plutarco, de Fluviis, IV, 6. Las afinidades dioscúricas de estos personajes han sido señaladas por A. Audin, «L'Omphalos de Lugdunum», Hommages Albert Grenier, vol. I, 1962, pp. 152164, en especial pp. 161-2; e IDEM, Lyon, miroir de Rome, París, 1979, p. 100. Para la etimología C. Sterckx, Dieux d'eau: Apollons celtes et gaulois, Bruselas, 1996, pp. 67-9.

${ }^{90}$ Tito Livio XXXVIII 16, 2-7; Memnón de Heraclea FrGrHist 434 F 11 = Focio, Biblioteca, 224, 227b-228a. 
argumento destacar que Estrabón distingue a Leonnórios como el jefe principal de la expedición, reflejando la idea de una jerarquía entre los dos jefes que ya hemos registrado en diversas ocasiones ${ }^{91}$.

4. Volviendo a la Galia, Polibio menciona a Concolitano y Aneroesto. Son reyes de los galos que viven en torno al Ródano movilizados para ayudar a los galos cisalpinos contra Roma (225 a. de C. $)^{92}$.

5. Los eburones estaban sub imperio de Ambiorix y Catuvolco, citado el último por César como rex de la mitad de la civitas, pero aparece sometido a Ambiorix que lleva la iniciativa ${ }^{93}$.

6. César favorece la sucesión entre hermanos. «los senones... poderosos y de mucho prestigio entre los galos, intentaron, por acuerdo público, matar a Cavarino, a quien César les había dado por rey y cuyo hermano Moritasgo ocupaba el trono al llegar César a la Galia, como lo habían ocupado antes sus mayores» ${ }^{94}$.

7. Los remos Icio y Andocumborio parecen regir a su pueblo sin aparecer nunca mencionados como reyes ${ }^{95}$.

8. Estrabón dedica un pasaje a la que considera antigua organización política de los galos: «Los regímenes aristocráticos prevalecían antaño entre ellos [describe la Galia Bélgica]. Desde la antigüedad elegían cada año un jefe (hegemón), y también para la guerra la multitud elegía a un jefe (strategós)» $»^{96}$. La noticia plantea muchos problemas. En primer lugar surgen dudas sobre su difusión geográfica, pues qué hacer entonces con los reyes y aristocracias «senatoriales» conocidas por otros testimonios ${ }^{97}$. En segundo lugar, está el

${ }^{91}$ Estrabón XII 5, 1. Es inevitable recordar a las parejas de jefes de germanos invasores atestiguadas en la antigüedad tardía, véase supra Apéndice 1, lo mismo puede hacerse en otros de los casos que siguen.

92 Polibio II 22; en II 26, Aneroesto parece tener cierta iniciativa. Pero en II 28, 10, se evoca a ambos reyes, precisamente cuando se presenta ante ellos la cabeza del cónsul romano caído en combate. En II 31, se indica que Concolitano cayó prisionero de los romanos y Aneroesto huyó pero se suicidó enseguida.

${ }^{93}$ César BG V 24, 4; V 26; VI 31, 5. Véase S. Lewuillon, Vercingétorix ou le mirage d'Alésia, Complexe, Bruselas, 1999, 137-8.

${ }^{94}$ César BG V 54, 2; Lewulllon, op. cit., 138-9. Otro caso de conflicto grave entre hermanos se produce entre los eduos Dumnorix y Diviciaco, respectivamente enemigo mortal y fiel aliado de César, pero el segundo no aspira a la realeza, probablemente porque es un druida, como indica Cicerón De divinatione I 41, 90, y F. Le Roux, Сh.-J. GuyonvarC'H, Les druides, Rennes, 1986, pp. 24-5. Entre los tréviros Cingétorix es yerno de Induciomaro, César $B G \mathrm{~V} 56,3$, con el que está enfrentado, César BG V 3-4 etc.; LEWUILLON, op. cit., 133-4.

${ }^{95}$ César, BG., II, 3, 1; 6, 4; LewUillon, op. cit., 125-6.

${ }^{96}$ Estrabón IV 4, 3.

${ }^{97}$ Véase el análisis de LewUiLLon, op. cit., pp. 81-108. 
sentido preciso que cabe atribuir a la distinción entre ambos jefes, sobre todo las eventuales funciones ¿religiosas? del primero. En tercer lugar se plantean todas las cuestiones derivadas de la elegibilidad, quiénes son electores, quiénes elegibles, en qué contextos. Por último, en el marco preciso de este trabajo, se plantea la eventual relación de parentesco entre ambos líderes que es, por ejemplo, la existente entre los hermanos Dumnorix y Diviciaco. Pese a estos problemas no creo que se pueda prescindir de esta noticia en el marco de la discusión planteada.

9. Si pasamos a las islas, tenemos que en el momento de la invasión de Claudio (51 d. de C.) Dion Casio describe una situación de gobierno de hermanos cuando señala que los sucesores en el gobierno del «imperio» catuvelauno de Cunobelino fueron sus hijos Carataco y Togodumno, sucesivamente derrotados por Plaucio ${ }^{98}$.

10. Seguimos en Gran Bretaña pero en otra época. Se trata de un ejemplo del País de Gales narrado por Geoffroy de Monmouth: «Desde la muerte de Dunvalón, sus dos hijos, Belino y Brenio, pugnaron por la sucesión al trono y por quién sería más digno de llevar la corona de Britania (diademate regni insigniretur). Después de que hubieron enfrentado en muchas batallas, los amigos de ambos decidieron intervenir y les hicieron llegar a un acuerdo. Pactaron que el reino se dividiera entre ambos de la siguiente forma: Belino tendría la corona de la isla (diadema insulae) junto con Logres, Cambria y Cornubia, pues era el mayor y la costumbre troyana exigía que la dignidad de la herencia recayera en el primogénito; Brenio, que era el menor, se sometería a su hermano y reinaría en Nortumbria, desde el Humber hasta Caithness. Un tratado solemne sancionó estos acuerdos, y ambos gobernaron el reino durante cinco años en paz y con justicia» ${ }^{99}$, después volvió a desencadenarse la guerra entre los hermanos. Le Roux y Guyonvarc'h indican además que el reparto del reino entre dos herederos es un hecho ordinario de la historia legendaria y medieval de los celtas. Además podemos resaltar algunos detalles que nos resultan familiares a través de otros testimonios. La diadema es símbolo de la realeza, existe una clara tensión entre los dos hermanos, y el acuerdo final establece una jerarquía clara entre ambos prevaleciendo el primogénito Belino sobre el más joven Brenio.

\footnotetext{
98 Dion Casio LX 20, 1-2.

99 Geoffroy de Monmouth Historia Regnum Britanniae, capítulo 35, trad. De Cuenca; véase el comentario de F. Le Roux, Ch.-J. Guyonvarc'H, Mórrígan - Bodd - Macha. La souveraineté guerrière de l'Irlande, Rennes 1983, pp. 163-4.
} 
11. Ejemplo irlandés de hermanos corregentes: «Diarmait y Bláthmac hijos de Aed Sláine estaban en Ulster disfrutando de su privilegio real de hospitalidad y recibieron a Cano con honor. Pero Aedán envió mensajeros con un gran tesoro de oro y plata que había capturado en Skye, ofreciéndoselo a los reyes si mataban a Cano...» sigue el lance con ambos reyes de acuerdo para rechazar la entrega del huésped ${ }^{100}$.

${ }^{100}$ M. DyLlon, The Cycles of the Kings, Dublín 1994, pp. 80-1. 